\title{
Sustainable Supply Chain Design in Social Businesses Advancing the Theory of Supply Chain
}

\author{
Bals, Lydia; Tate, Wendy L.
}

Document Version

Accepted author manuscript

Published in:

Journal of Business Logistics

DOI:

$10.1111 / \mathrm{jbl} .12172$

Publication date:

2018

License

Unspecified

Citation for published version (APA):

Bals, L., \& Tate, W. L. (2018). Sustainable Supply Chain Design in Social Businesses: Advancing the Theory of Supply Chain. Journal of Business Logistics, 39(1), 57-79. https://doi.org/10.1111/jbl.12172

Link to publication in CBS Research Portal

\section{General rights}

Copyright and moral rights for the publications made accessible in the public portal are retained by the authors and/or other copyright owners and it is a condition of accessing publications that users recognise and abide by the legal requirements associated with these rights.

Take down policy

If you believe that this document breaches copyright please contact us (research.lib@cbs.dk) providing details, and we will remove access to the work immediately and investigate your claim. 


\section{Sustainable Supply Chain Design in Social Businesses: Advancing the Theory of Supply Chain}

\section{Lydia Bals and Wendy L. Tate}

Journal article (Accepted manuscript*)

\section{Please cite this article as:}

Bals, L., \& Tate, W. L. (2018). Sustainable Supply Chain Design in Social Businesses: Advancing the Theory of Supply Chain. Journal of Business Logistics, 391), 57-79. 001: 10.1111/jbl.12172

This is the peer reviewed version of the article, which has been published in final form at DOI:

$$
\text { https://doi.org/10.1111/jbl.12172 }
$$

This article may be used for non-commercial purposes in accordance with Wiley Terms and Conditions for SelfArchiving

* This version of the article has been accepted for publication and undergone full peer review but has not been through the copyediting, typesetting, pagination and proofreading process, which may lead to differences between this version and the publisher's final version AKA Version of Record. 


\title{
SUSTAINABLE SUPPLY CHAIN DESIGN (SSCD) IN SOCIAL BUSINESSES: ADVANCING THE THEORY OF SUPPLY CHAIN
}

\author{
Lydia Bals \\ University of Applied Sciences Mainz; \\ Copenhagen Business School \\ Wendy L. Tate \\ University of Tennessee
}

\section{Please cite as:}

Bals, L., \& Tate, W.L. (Forthcoming): Sustainable Supply Chain Design (SSCD) in Social Businesses: Advancing the Theory of Supply Chain, Journal of Business Logistics.

\begin{abstract}
A significant conceptual and practical challenge for companies is how to integrate triple bottom line (TBL) sustainability into their global supply chains. In supply chain research, the classic economic perspective - the business of business is to be profitable - still dominates, followed by coverage of the environmental dimension; the social dimension is underrepresented. Stakeholders, however, are calling for a TBL perspective that simultaneously includes environmental, social and economic gains. While there have been recent theoretical advances on how to characterize supply chains in terms of their structure, how to connect these insights to supply chain design for TBL sustainability has not been studied. Therefore, the purpose of this research is to move the theory of supply chain forward into the sustainable supply chain management (SSCM) research agenda. Toward that purpose, the paper analyzes the sustainable supply chain design (SSCD) at social businesses, incorporating the physical chain and the information and financial support chains. Four social businesses located in Haiti are used as cases of innovative supply chain structures for TBL sustainability. By analyzing the supply chain structures and boundaries of these social businesses, three supply chain configurations combining physical and support chains are presented.
\end{abstract}

Keywords: sustainability, environmental issues, ethics, social responsibility, Supply Chain Management, Triple Bottom Line, case study research 


\section{INTRODUCTION}

A significant conceptual and practical challenge is how to integrate sustainability into global supply chains. Many highly publicized issues fall outside the realm of the profit and loss statement but are critical for the survival of the firm and the survival of populations. Consider, for example, that, according to the United Nations, the availability of clean water is lacking and negatively impacts about 783 million people around the globe (UN Water 2013). Another telling example of the global sustainability challenge is that of consistently rising temperatures due to climate change where countries signed the Paris Treaty committing to a global action plan that puts the world on track to avoid dangerous climate change (European Commission 2015). These two examples illustrate that the time for academics and practitioners to consciously rethink supply chains (or reshape value chains) has come (Howard-Greenville et al. 2014)., as unpurposeful design could have negative environmental, social and economic implications (Varsei and Polyakovskiy 2016). Accordingly, questions regarding how to redesign supply chains to manage risk and improve sustainability have been moving up the supply chain management research agenda (Wieland et al. 2016; Bode and Wagner 2015; Durach et al. 2015).

It is challenging for managers to think about, and even more so to invest in, long, uncertain payback periods. These managers may also believe that certain areas of the world are not critical to business survival and the issues that relate specifically to those areas are the problems of governments and non-governmental organizations (NGO's) (Fawcett and Waller 2015). But businesses increasingly have to recognize that there are significant tradeoffs inherent in doing business that involve many other stakeholders and outcomes that focus on TBL sustainability objectives (Elkington 1998) rather than profit or cost outcomes. Governments and NGOs are part of doing business around the world and are therefore part of the network of stakeholders that share in triple bottom line success. In contrast to such traditional economic foci in business, social 
businesses offer insights into a laboratory of sustainable supply chain designs. Social businesses strive to address multiple objectives, economic and social and/or environmental simultaneously and pursue impacts that address stakeholder issues holistically (Lyons 2013) on both the demand and supply side (Thake and Zadek 1997). Social business models aim at value creation by addressing economic, environmental, and social elements, and promoting equitable relationships among stakeholders, and by adopting a fair revenue model (Boons and Luedeke-Freund 2013). Social business models can be deployed by firms of varying sizes and start-ups (e.g. Pura Vida Coffee; Wilson and Post 2013) or established firms (e.g. the Grameen Danone collaboration; Yunus et al. 2010).

The current sustainable supply chain management (SSCM) research mainly addresses the economic and environmental dimensions of the TBL, but suggests, "[a] comprehensive analysis of sustainable business operations should consider all three TBL dimensions simultaneously" (Wu and Pagell 2011, 589). There is a clear need for further research into the issues of "how to create [emphasis added] truly sustainable supply chains" (Pagell and Shevchenko 2014, 44-45). Similarly, it has been emphasized that as "stewards of knowledge creation and dissemination, it is necessary to conduct in-depth, nuanced research to help decision makers understand how to think, design, and deliver differently (Fawcett and Waller 2011)" (Fawcett and Waller 2015, 238). This emphasis on creation/design of sustainable supply chains highlights the necessity to reconsider how supply chain design is approached in research and practice. Analyzing social businesses as firm types that have been founded with TBL performance objectives as part of their design, instead of analyzing cases of retrofitting economically-oriented businesses for improvements in the social and/or environmental dimensions thus offers a fresh perspective. 
When turning toward the question how the designs support sustainability, it is necessary to define both the design parameters and the structural elements. Whereas the former was mentioned above as TBL criteria, the latter have only been subject to recent theory development. Specifically, the theory of the supply chain (Carter et al. 2015) offers supply chain structures and boundaries that surround supply chain design. However, in developing this theory the authors emphasize that there is a major omission in supply chain conceptualization: the indirect or more supportive players are largely ignored (Carter et al. 2015). This is a major issue because no pair of firms within a supply chain network operates in isolation from others (Ford 1990), and previous research on sustainability in supply chains has emphasized the importance to take stakeholders into account (Matos and Hall 2007; Matos and Silvestre 2013). Currently, the theory of supply chain predominantly considers economic stakeholders (i.e. businesses and financial institutions), and has not yet incorporated other non-economic stakeholders.

The specific research objective of this study is to initiate understanding of the supply chain design for achieving TBL sustainability by elaborating the theory of the supply chain (Carter et al. 2015) toward a theory of sustainable supply chain design (SSCD), and promote additional research on this phenomenon. To clarify what is considered "theory" in this research, Wacker (1998) is followed, structuring the discussion along the four main components of theory: 1) definitions of terms or variables; 2) identifying a domain where the theory applies; 3) determining a set of relationships of variables; and 4) making specific predictions (factual claims). In this research, the theory forming the basis of the conceptual development is the theory of the supply chain, which was relatively recently put forward by Carter et al. (2015). The first research question relates to the first theory component (variables) and the second component (domain). The second question extends the scope to components three and four (relationships and predictions). The research 
questions being addressed are: 1. How are supply chain structures of sustainable businesses designed to deliver on TBL objectives? The first research question refers to the stakeholders in scope, the design parameters and the structural elements of the supply. 2. How do the different configurations support sustainability? The second research question refers to a more detailed view on the design parameters and how they are operationalized as TBL outputs versus outcomes. Forprofit social businesses in Haiti are used to discuss supply chain configurations, or design models, of TBL sustainable chains. Despite having "social" in the title, these businesses pursue economic, social and environmental objectives. From the inception of these sustainable, social businesses, the mission-driven entrepreneur focuses on building TBL sustainability into the supply chain to design a sustainable social business model and convince social investors of the return-oninvestment in all three pillars of sustainability.

The research questions are addressed by first summarizing supply chain design parameters which are usually centered on physical supply chain outputs and their direct (economic and environmental) consequences, such as carbon dioxide $\left(\mathrm{CO}_{2}\right)$ emissions from the transport of goods. Sustainable business models and outputs versus outcomes are then defined by highlighting the idea of looking beyond physical material flows (and their outputs) to outcomes of physical, information and financial support chains (Carter et al. 2015). The theory elaboration methodology is described next, followed by the translation of TBL design parameters into three supply chain configurations, with the results summarized into an elaborated theoretical model to spur further research into SSCD.

\section{THEORETICAL BACKGROUND}

The initial theoretical framework is based on the theory of the supply chain (Carter et al. 2015), and a review of the supply chain design literature is summarized in Figure 1, which highlights the 
current research focus on the economic and environmental dimensions first, and then subsequently on outputs and the physical chain. The respective theory components, 1 (variables, i.e. design parameters and elements), and, 2, (i.e. domain) are discussed in the sections below.

\section{[Please insert Figure 1 about here]}

\section{Design parameters and elements in current supply chain design: Focused on economic and} environmental design criteria and the physical chain

In the current literature, the search for TBL performance of supply chains usually is centered on how to improve environmental performance in established supply chains (e.g. Handfield et al. 1997; Christmann 2000; Melnyk et al. 2003; Zhu and Sarkis 2004; Wu and Pagell 2011), and not on the design phase of sustainable supply chains. This research is interested in how supply chains are created structurally to achieve TBL objectives from inception rather than how established chains try to reduce negative TBL outcomes later (or retrofit the supply chain to meet different stakeholders needs); hence the focus is on the design phase.

In supply chain design (or supply chain network design) 1, the more traditional metrics of economic performance are applied, leading to a rather narrow scope of delivery from a TBL perspective. The majority of the literature on supply chain modeling during the 1990s focused on costs. This included cost minimization (e.g. Tzafestas and Kapsiotis 1994; Lee et al. 1997; Vidal and Goetschalckx 1997), minimization of average inventory levels (e.g. Towill and del Vecchio 1994), minimization of obsolete inventory (e.g. Ishii et al. 1988) and maximization of profits (e.g. Cohen and Lee 1989). Other focus areas are customer responsiveness, flexibility and combinations

\footnotetext{
1 The definitions of what supply chain network design comprises again highlight a clear focus on the physical material flows in current research, as it is centered on decisions about number, location and capacity of facilities such as production plants, distributions centers and supplier selections (Eskandarpour et al. 2015; Varsei and Polyakovskiy 2016).
} 
of cost (Beamon 1998). Typically, supply chain design centers on the physical chain, e.g. facility locations, supplier locations, and related physical material flow logistics. In a comprehensive literature review, Meixell and Gargeya (2005, 536-537) emphasize these physical focus decision variables as facility selection, production quantities and supplier selection, and highlight the economic performance constructs.

"Sustainability introduces less quantifiable considerations relating to the natural environment and in some cases social issues" (Linton et al. 2007, 1080). While there is an increasing coverage of supply chain metrics addressing the triple bottom line (Parmigiani et al. 2011; Searcy 2012; Hassini et al. 2012; Seuring 2013; Hussain et al. 2016), literature addressing how to take such parameters into account already in design is still scarce (Chen et al. 2014; Eskandarpour et al. 2015). Typically, in the supply chain design literature there are at most two dimensions of the triple bottom line considered together, economic and then environment or social. The majority of supply chain modeling papers take into account one or two dimensions, but very few all three (Seuring 2013). Green supply chain management (e.g. Zhu and Sarkis 2004; Beamon 2005; Sarkis 2006; Vachon and Klassen 2006; Srivastava 2007; Tate et al. 2010), for example, focuses on the economic and environmental dimensions. Xia et al. (2015) consider economic and social together (i.e. financial performance effects of a proactive social responsibility strategy). Other research focused on the environmental aspects of reducing the carbon footprint as part of the supply chain design parameters (Cruz and Matsypura 2009; Sundarakani et al. 2010; Harris et al. 2011; Wang et al. 2011; Mallidis et al. 2012; Jin et al. 2014; Mallidis et al. 2014), making location decisions for profit maximization and environmental parameters (Krikke et al. 2003; Hugo and Pistikopoulos 2005; Neto et al. 2008). 
Accepted version status March 2017; Journal of Business Logistics (JBL)

All three legs of the TBL are rarely represented, particularly as it pertains to supply chain design parameters. In their recent review of the literature on sustainable supply chain network design, Eskandarpour et al. (2015) found that only 10 out of 87 identified papers cover all three areas. Two notable exceptions in the last years are the work by Ramudhin et al. (2010), who searched for an optimal distribution center location and transport mode to minimize costs (e.g. in purchasing, production, warehousing), environmental considerations of greenhouse gas emissions, and also at least mentioned social considerations, which could be captured by evaluating the improvement of standards of living and quality of life in the communities around the supply chain, and Chaabane et al. (2011; 2012), who further developed this research. Also, very recently, Varsei and Polyakovskiy (2016), motivated by the lack of studies with a simultaneous coverage of all three dimensions, performed a case study analysis in the Australian wine industry.

These studies, however, still have a tendency to center on redesign scenarios, and they clearly focus on facilities and the physical material flow. Moreover, these latest papers also do not yet embrace a sequencing of the TBL dimensions, e.g. in line with the recently proposed ecologically dominant logic (Montabon et al. 2016), in which the sequence to assess intended corporate strategies and actions is to determine first environmental, second social and then economic viability.

\section{Broadening the design elements: Physical and support chains in the theory of the supply chain}

It is important to note that other recent studies venturing into the area of sustainable supply chain design still kept their definition of supply chain design rather close to the physical material flow focus, and in line with that which kept focusing on the entities involved in those physical flows. For example, in a definition followed by Varsei et al. (2014, 243): “The design or reconfiguration 
of a supply chain is considered as a strategic goal aiming at determining the number, location and capacities of manufacturing plants and distribution centres, the set of suppliers to select and the effective flow of material throughout the supply chain".

Recently, Carter et al. (2015) advanced supply chain theory by suggesting a differentiation between the physical chain and support chain(s). The physical supply chain, in which the physical products move from supplier to focal firm to customer, is differentiated from the support supply chain, which concerns the movement of information and movement of finance. The support supply chain is defined as "consisting of nodes through which a product (relative to the focal agents) does not flow, but which support the physical supply chain of that product" (Carter et al. 2015, 8), like embedded financial institutions. Carter et al. (2015) also suggested that many different configurations of the physical and support supply chain are possible. Carter et al.'s (2015) primary figure showing these physical and support chain configurations is reproduced in Figure 2.

\section{[Please insert Figure 2 about here]}

For social businesses designing their supply chains to be TBL sustainable from the beginning, in the context of severe financial, human resources and environmental constraints, the differentiation of a physical chain and support chain is not only necessary to characterize the chains that the social businesses employ, but that it is actually the appropriate design of the support chain (particularly related to financial flows) that can become a vital precondition for TBL success. For example, impact investing (as a support flow) plays a particular role in funding these businesses

to ensure that supply chains are well designed and executed, especially in the early phases of business model development when the social business is most vulnerable (Grabenwarter and Liechtenstein 2011). An impact investment is defined as an investment with the intent to create 
Accepted version status March 2017; Journal of Business Logistics (JBL)

measurable social or environmental benefits in addition to a financial return (Wood et al. 2013) and these are a part of the complex financial support chains needed for these businesses.

\section{Connecting stakeholders and the design parameters: TBL outputs versus outcomes}

There is a strong indication in supply chain management research that different types of business models exist to balance economic and environmental objectives. The social dimension within these models, however, is largely ignored (Wu and Pagell 2011) and the involvement of stakeholders is rarely studied (Matos and Hall 2007; Matos and Silvestre 2013). The social dimension is defined as "Social sustainability in supply chains addresses issues of social justice and human rights with studies focusing on practices such as supplier human rights actions, labor conditions, codes of practices and social auditing, supplier compliance with child labor laws, and the delivery of social equity through sourcing from diverse suppliers in terms of gender, size, ethnicity and avoidance of conflicts of interest"' (Eskandarpour et al. 2015, 19). The social entrepreneurship literature offers some research that helps link "social" with "business model" in the context of supply chain management research. The business model consists of the content, structure, and governance of transactions designed to create and deliver value through the exploitation of business opportunities (Amit and Zott 2001). "[A] business model describes the rationale of how an organization creates, delivers, and captures value" (Osterwalder and Pigneur 2009, 14).

A social business model is "a system of independent activities that transcends the local firms and spans its boundaries" (Amit and Zott 2010, 217) that does not try to maximize profits, as is the case with typical businesses, but instead focuses on the "most pressing" societal needs. Formulating social business models requires new value propositions, value constellations and profit equations, not unlike business innovation (Yunus et al. 2010). According to Márquez et al. (2010) a social business has to be self-sustaining, profitable and based on the premise of 
transforming the standard of living of a specific region. Thus, the boundaries of what stakeholders to include are expanded rather widely, i.e. captured as to include economic, environmental and social stakeholders simultaneously. Second, this value creation for the stakeholders may be achieved by specific products and/or by how value is delivered. This is further differentiated into outputs versus outcomes.

Products as outputs and the related physical material flows are usually at the center of supply chain research (e.g. Seuring, 2011), whereas value as outcome is usually not. Highlighting the current focus, research has suggested that "sustainability also must integrate issues and flows that extend beyond the core of supply chain management: product design, manufacturing byproducts, by-products produced during product use, product life extension, product end-of-life, and recovery processes at end-of-life" (Linton et al. 2007, 1078). For the remainder of this paper, sustainable outputs versus outcomes are defined as follows.

Sustainable outputs are defined as the items or services that are produced by a person, machine or industry with the specific purpose of meeting TBL sustainability goals (including the adaptation of existing products) for consumers, including those with fewer resources or a different cultural background. Examples are affordable eco-shampoo, cell phone time sold by the minute, laundry detergent in bulk, and multi-purpose washing machines that clean laundry, dishes and vegetables (Prahalad 2006).

Alternatively, sustainable outcomes are the effects of projects, processes or business models designed specifically for meeting TBL sustainability goals for consumers, including those with fewer resources or different cultural backgrounds. Examples are $\mathrm{CO}_{2}$ offsetting for flights, as well as chicken farms or a bakery model for funding schools (Yunus et al. 2010). 
Outputs correspond to the products moving along the physical chain and the economic, environmental and social effects directly connected to that flow. Outcomes correspond to TBL results achieved via support chains in the design.

\section{Definitions and terminological clarity: Defining Sustainable Supply Chain Design (SSCD)}

In order to elaborate the theory of supply chain towards a theory of SSCD, this research builds on established supply chain (Mentzer et al. 2001; and Carter et al. 2015) and sustainable supply chain management definitions (Seuring and Müller 2008) highlighted in Table 1.

\section{[Please insert Table 1 about here]}

The resulting definition for SSCD is the design of physical material, information and capital flows as well as cooperation among companies along the supply chain according to TBL design parameters, which are derived from economic, environmental and social stakeholder requirements in order to achieve TBL effects (outputs and outcomes).

This research puts forward that the design aspects of SSCD replace the management aspects in the more general SSCM definition. This broadens the criteria beyond the economic focus in supply chain design to also include environmental and social issues. Moreover, it includes all three flows - material, information and capital.

\section{METHODOLOGY}

\section{Research design}

This research engages in theory elaboration which focuses on the contextualized logic of a general theory, in this instance the theory of the supply chain (Carter et al. 2015) using cases in Haiti where it is challenging to develop detailed premises used in conjunction with the general theory (Ketokivi and Choi 2014). The cases are meant to elaborate sustainable supply chain design in pursuit of analytic generalization "at a conceptual level higher than the specific case" (Yin 2014, 42). 
Contrary to the traditional foci in research highlighted in Figure 1, social business models offer insights into a SSCD laboratory. From the inception of social business ideas, TBL impact is the explicit goal and a significant caveat for the availability of funding. Designing in TBL impacts can have an immediate output (product) focus that meets TBL outcomes, or an intermediate TBL outcome focus. The businesses and their support chains are designed in ways that support either perspective and combine the physical, financial and information chains in different ways.

As opposed to theory testing or development, theory elaboration is suitable when there exist conceptual ideas that can serve as the foundation of the empirical research, but premises are not sufficiently detailed to deduce hypotheses for testing (Lee et al. 1999; Ketokivi and Choi 2014). Based on abductive reasoning, theory elaboration emphasizes the interplay between empirical data and theory simultaneously (Dubois and Gibbert 2010). Data serves to illustrate and elaborate (Ketokivi and Choi 2014). In this research, the conceptual framework presented in Figure 1 (summarizing the TBL design parameter literature in combination with the structural design elements and boundaries by Carter et al. 2015) provides the overall theoretical framework that is used as the basis of the empirical study and then evolves into a more detailed framework with the empirical analysis (Dubois and Gibbert 2010).

The literature on supply chain theory as well as supply chain design was used as a foundation to provide the boundaries and parameters for a model that is testable and likely empirically valid (Eisenhardt 1989; Ketokivi and Choi 2014). For data collection, an interview guide (Appendix A) was developed around the antecedents and mechanisms of implementing TBL objectives into global value chains.

\section{Selection criteria and selection procedure for the cases}


Research on larger firms shows a sequential multiple step approach of integrating TBL concerns. Porter and Kramer (2006) described how many companies responded only after being surprised by public responses to issues that they previously ignored as their responsibility, such as Shell's Brent Spar decision (sinking an obsolete oil rig) or Nike and the reports on its abusive labor practices in Indonesia in the early 1990s, and then responded cosmetically (e.g. with public relations and media campaigns). In contrast, social businesses are arranged differently with a mission-driven approach where TBL sustainability is designed in at conception, permitting a look into a laboratory of sustainable and innovative business models (Tate and Bals, Forthcoming).

In early 2014 one of the researchers attended various events on social businesses in order to look for suitable cooperation partners for data collection. One of these events was organized by Yunus Social Business (YSB) in Frankfurt, Germany. From a SSCM perspective, YSB's way of supporting social businesses to achieve sustainability objectives throughout a diverse range of countries resonated very promisingly with the earlier mentioned calls for more research into how sustainable supply chains can be created/designed (Pagell and Shevchenko 2014; Fawcett and Waller 2015). Therefore, right after the event, YSB was approached for data collection and the YSB headquarters in Germany helped to select the appropriate country and the respective social businesses to be studied in detail.

Country selection followed the selection criterion that the country needed to have social businesses that had been established for more than two years to allow the researchers to follow the social businesses' trajectory. Also, as a second criterion, the specific location had to offer serious resource constraints to observe how supply chains are designed to overcome these constraints. This led to the selection of catastrophe-ridden Haiti, one of the countries where YSB has its longest presence. Haiti was selected as a context because of serious economic, environmental and social 
constraints. The people in Haitian communities live in levels of extreme poverty with limited access to goods and services. The earthquake that hit the country in 2010 has had lingering environmental, economic, and social impacts. Also, less than $1 \%$ of the natural forests still exist in Haiti, causing additional TBL challenges.

For the specific social business selection, YSB sent their complete portfolio of operating and prospective social businesses in Haiti to the research team. The profiles were analyzed for coverage of the three sustainability dimensions and the different business models. The tentative case selection was then discussed with the Haiti Country Manager at YSB (interviewee A) to determine which cases from the Haiti portfolio would fulfill the requirements, i.e. to pursue TBL criteria and already be in the initial stages of execution of the plan to better understand physical material, information and financial flows, and stakeholder network connections.

The selection logic followed both the criteria to have extreme cases (in a resource-scarce environment, i.e. Haiti) and being paradigmatic (i.e. supply chain structures of three different business models) by design (Flyvbjerg, 2006). Also, YSB noted that it has three different business model types, so cases were selected with this in mind. This led to the selection of the three social businesses EPRO, CHIFA CLEAPRO (not their real names, but anonymized). The social business EPRO offers cooking (e.g. stoves) and lighting products (e.g. solar lamps). CHIFA is a social business producing chicken meat as a way to generate funding for a school. CLEAPRO is a social business offering cleaning products such as detergents (cleansing agents that are effective for washing dishes and clothes), disinfectants (substances applied to non-living objects to destroy microorganisms that are living on these objects) and bleach (used to disinfect surfaces, remove stains, whiten clothes or also purify drinking water). 
Accepted version status March 2017; Journal of Business Logistics (JBL)

During the analysis of these three social businesses it became evident that one of them (CLEAPRO) actually had a "mixed" model, instead of being a clear-cut model. Therefore, the Haiti country manager helped identify a more clear-cut case from their portfolio for additional analysis. This led to further inclusion of COSMO (again, anonymized). COSMO is a social business built around the ingredient castor oil that delivers premium cosmetic products to the US market, but in the process creates jobs (particularly for disadvantaged women) and is environmentally friendly.

\section{Data collection and analysis}

The first step of data collection after the data collection approval by the YSB headquarters was to contact the Haitian country manager (interviewee A in Table 2), who sent the researchers the investor summaries of all social businesses within its portfolio.

\section{[Please insert Table 2 about here]}

Based on the selection criteria mentioned, a first interview with the Haitian country manager was scheduled to discuss a list of potential cases. In that interview, the results of the portfolio analysis of the researchers was discussed (e.g. to ensure that indeed the understanding regarding the coverage of TBL criteria was correct) and three social businesses were selected. After that interview, the country manager established direct contact to each of these three social businesses and interviews with them were scheduled. In parallel to the scheduling, the researchers were provided with these businesses' full business plans (both text and calculations), profit and loss statements, YSB eligibility and investment criteria, extended investor summaries (these are standardized documents required by the headquarters in Germany and include objectives, (financial) investment required, context, business model, and social impact). In preparing for the interviews with the interviewees, the two researchers worked through these materials and 
summarized their current understanding (e.g. regarding the three flows and stakeholder situation). This understanding was then challenged in another interview with the Haitian country manager, who provided answers for all three businesses. The interviews with the three businesses then were conducted (interviewees B, C and D in Table 2).

During all interviews, two researchers were present, to ensure clarity and understanding of the information provided. During or after the interviews, the social businesses also provided some additional materials (e.g. their most up-to-date organizational charts). All of the interviews were transcribed and the overall database enriched by field notes of the researchers. While the data collection in the social business interviews followed the interview guide (Appendix A), some questions were open-ended, allowing for direct or follow-up questions. For content validation, the interview summaries were sent to the interviewees and they were contacted for additional information and clarification as the coding process continued (e.g. some stakeholder names in French had to be clarified).

Later, the social business interviewees were also provided their respective full within-case assessment to ensure that their respective analysis was accurate. The interviewees either confirmed accuracy or gave us instructions on how to correct the results (e.g. when we showed the different flow charts, the interviewees would sometimes add another line or box, or further specify where cash versus bank accounts are utilized in the financial flow charts).

As mentioned in the previous section, the analysis of EPRO, CLEAPRO and CHIFA actually led to the conclusion that the case CLEAPRO was a mixed model. After the within-case and cross-case results had been provided, interviewee A (the country manager) gave us feedback that she thought that YSB would be able to nominate a more clear-cut case for a third configuration. Therefore, upon reflection of this research's scope and intermediate results, COSMO was offered 
as a fourth case. As a result, COSMO's additional data were provided to the researchers and interviewee A was available for another interview on COSMO. Since a more clear-cut third configuration could be well-described from COSMO's materials as well as the interview with interviewee A, it was concluded that another interviewee would not be needed.

As summarized in Table 3, apart from validating intermediate and final results with the interviewees, the use of multiple sources such as the social businesses' public website information and their proprietary data mentioned above were used to compare interviewee information with additional documentation (e.g. on the objectives pursued) and served to mitigate biases and enhance reliability and validity (Jick 1979; Eisenhardt 1989; Yin 2014).

\section{[Please insert Table 3 about here]}

Regarding the analysis as such, the foundational literature was combined with the data from the cases to continue the theory elaboration beginning with the conceptual framework in Figure 1. All of the case input was coded based on the literature review (stakeholders, design parameters, structural elements, outputs and outcomes) plus open coding. Particular focus was placed on which design parameters and structural elements the cases display (the main variables, theory component 1), how broadly the cases define their stakeholders (the domain, theory component 2) to achieve their TBL outcome objectives (relationships between the variables, theory component 3 ), and factual claims (theory component 4). In the next section, to ease readability with a clear flow of argumentation, the results will be covered in the following order: First, domain (which stakeholders are in scope); second, relationships and factual claims (which are the configurations in the cases and what do result in); and third, more details on the variables (design parameters and structural elements). 


\section{CASE RESULTS ON SUSTAINABLE SUPPLY CHAIN DESIGN (SSCD)}

Results on the scope of the domain: Connecting stakeholders to TBL design parameters and

\section{supply chain flows}

After analyzing the data, a key understanding was that early on in the process of defining their business model and designing the appropriate physical material and supplemental flows, the interviewees sought to understand how to deliver (and to whom to deliver) sustainable TBL value. Their networks were often complex with competitors, NGOs, government, communities, suppliers and many others that had some stake in what was defined "value". Table 4 presents the stakeholders of EPRO and CHIFA and the respective stakeholder's involvement in the three different types of flows.

\section{[Please insert Table 4 about here]}

YSB was directly connected to all of the businesses and had a stake in its ultimate success. Another role of YSB was to help identify the stakeholders and also help define the requirements for delivering the appropriate stakeholder value. Each of the businesses also had varying governmental stakeholders with specific requirements for the Haitian community, and the appropriate governmental representatives had to be identified and assured that their specific requirements were being met. A statement by interviewee $\mathrm{C}$ from $\mathrm{CHIFA}$ serves as an example: "When we had the opening of the farm in [city], we had the Minister of Animal Production come to the party. So they're kind of open [...], but they don't have that much resources. We're not going to count on them for resources. We might count on them [...] in terms of supporting us if we need some paper as if we need to do something that requires government support."

A number of financial organizations also played an important role in the initial establishment of the social business, specifically before the business reached break-even or profitability. In the case of the social businesses, it was important to recognize these financial 
Accepted version status March 2017; Journal of Business Logistics (JBL)

organizations as supporting links, not necessarily ties to the flow of goods or services. The financial organizations helped the consumers to be able to afford and/or establish credit, or simply manage the flow of funds. These financial institutions also helped to bridge the request for goods from a supplier until payment to the supplier was made. The financing aspect became critical in bridging the supply and demand sides of the chain (ordering and receiving products then delivering value to the customer). For example, as interviewee B from EPRO stated when explaining who played a major part in establishing the business: "Finally, I have also to speak about our Microfinance institution partner [with whom I have a] crucial partnership for my business model. "

There is a business lifecycle in these social businesses where certain stakeholders played more critical roles at different points. For example, major financial contributors, such as YSB (for both financial resources and expertise) and the banks/financial institutions and impact investors, played an early significant role. For EPRO, one very important event in its early business development was organized by its stakeholder, the United States Agency for International Development (USAID), in the context of its ICTP (Haiti's Improved Cooking Technology Program). USAID brought together "[...] stakeholders of the value chain, and that program invited some different banks and YSB and others, and then we could speak with them [...] and then we started to work together." After the business had about one year of piloting experience, YSB participated in further developing the business plan " [...] to go deeper into detail; get something stronger” (Interviewee C), reinforcing stakeholder involvement and commitment.

COSMO's stakeholders are particularly comprised of YSB, the local community and customers. CHIFA's key stakeholders included a Haitian NGO (HNGO) (as a provider of financial resources as well as expertise), Heifer (a provider of specific agricultural expertise), JAMCHI (as the single suppliers of physical resources, i.e. chicks, fodder, and the related veterinarian services) 
Accepted version status March 2017; Journal of Business Logistics (JBL)

as well as YSB (as a provider of funding, business expertise and tools, and also in establishing connections to and exchange with other social businesses).

All of the social businesses considered their stakeholders as part of the design process. The social businesses identified what adds value, then incorporated those needs as part of the design.

\section{Results on the relationships between variables: Three TBL sustainable supply chain configurations}

Three basic TBL sustainable supply chain configurations were identified. The schematic designs of the three types of models developed through discussion and other documents obtained from social businesses in Haiti can be seen in Figure 3. The physical chain is depicted by full lines and its nodes as ovals, and the financial support chain has dashed lines with its nodes as rectangles, as was done by Carter et al. (2015) and as was also shown in Figure 2). The information chains exist between all stakeholders, but information flows in both directions and to many more entities (see Table 4) than depicted here. Although these three models have a specific orientation towards outputs and/or outcomes, it is central to their design that they ultimately cover the TBL.

\section{[Please insert Figure 3 about here]}

- Configuration 1 (e.g. EPRO) - Social Product Model: For this model, the product/service did not exist before and is now offered by a social business (e.g. case with energy solution). The physical chain directly delivers social products as the main purpose. A supporting financial flow to improve accessibility of the social products has been designed in purposefully.

- Configuration 2 (e.g. CHIFA) - Auxiliary Financial Chain Model: This model has no operations that service its primary purpose, so there needs to be an auxiliary business that funds the prime activity (e.g. cases of chicken farms for school funding). The physical chain delivers a product, but the financial chains are what fulfills the main purpose of funding education. 
Accepted version status March 2017; Journal of Business Logistics (JBL)

- Configuration 3 (e.g. COSMO) - Positive Externalities Model: Jobs in the value chain are created (e.g. COSMO), the product is not considered a socially focused product/service per se. The physical chain delivers a product, but the positive externalities of the business to the community are the main purpose.

To illustrate different configurations regarding their physical material and support flows, EPRO and CHIFA are discussed next. These two were chosen for further illustration as EPRO includes the financial support chain with a micro credit institution and CHIFA itself represents a business that creates a financial chain towards a non-traditional stakeholder (i.e. a school). What is interesting to note is that the physical material flows involved fewer participating entities than the financial and information flows (see also Table 4).

Within EPRO's model, the physical material flow on the supply side has the social products coming from a number of suppliers, both from within (if available) and outside the country (e.g. India). Total, or more specifically "Awango" (the social entrepreneurship initiative by Total), is the supplier for the imported solar lamps and cooking stoves. Awango provides these products with affordable prices to explicitly serve base of the pyramid customers. The sales model revolves around a number of flagship stores and distributing products via trucks and motorbikes to a network of retailers. While the physical chain is rather typical, the financial support chain is considered very important to the success of the social business and, for EPRO, is depicted in Figure 4 below.

\section{[Please insert Figure 4 about here]}

EPRO's financial flows comprise investments for funding the business by a European NGO (ENGO), YSB, and Grameen Crédit Agricole. The financial flows incurred by actual sales have another intermediary that plays an important role: IDE Microfinance. This microfinance 
institution provides end customers unable to pay the price of products in one sum with low-interest credit and gives them a check with which they can pay EPRO. The loan repayments to IDE Microfinance are then made in small amounts via Western Union due to the lack of widespread use of bank accounts. The information flows follow these same relationships, but occur both ways. Moreover, additional mutual flows occur between the focal business and its diverse range of stakeholders (mentioned in Table 4).

At CHIFA, the supply side is dominated by JAMCHI as the single supplier of chicks, fodder as well as veterinary assistance. The sales model largely revolves around the local community. Locally, it is very well known that the farm is generating income to fund the local school, so parents, relatives and other community members simultaneously act as supporters (e.g. when small repairs have to made) and customers. CHIFA has also identified customers such as international hotel chains and restaurants, which are interested in fresh and natural chicken meat. The related flows are shown in Figure 5. The money to support the start-up of the business comes from HNGO and YSB. Regarding the financial flows incurred by actual sales, the local end customers usually pay cash, whereas the envisioned sales with hotels and restaurants would be with checks, later to be cashed in at banks. Here, CHIFA itself acts as a support financial chain to create a means to an end - funding schools. Also, JAMCHI grants CHIFA a 2-month payment period, basically granting them a credit line to reduce the potential strain on cash flow.

\section{[Please insert Figure 5 about here]}

\section{Results on variables: Structural elements and TBL sustainable outputs versus outcomes}

Environmental, social and economic outputs (e.g. affordable products) and outcomes (e.g. education via funding a school etc.) that were uncovered are shown in Table 5 and 6 . All of these social businesses are defined as "for-profit" and aim for continuous perpetuation.

\section{[Please insert Tables 5 and 6 about here]}


Coverage of all three dimensions is in all of the social businesses, being it via outputs and/or outcomes; e.g., COSMO only covers economic outputs directly, but, via improving the women's economic situation and closed-loop waste management (the residue can be used as fertilizer) it achieves social and environmental outcomes, respectively. These businesses do not only use outcomes to compensate for missing output dimensions, but they also aim at a broad coverage of TBL outputs and outcomes to advance their missions. What this shows is that businesses without sustainable products (outputs) can still achieve sustainable outcomes by designing these outcomes into their supply chains via additional information and financial chains. For example, while CHIFA's outputs (chicken meat) only cover the social and economic dimension, its cooperation with Heifer (information chain) to address the environmental side (outcome) has made it cover also the environmental dimension.

This substitution aspect is graphically illustrated in Figure 6 by building on previous work highlighting the intersections of the three sustainability dimensions (Carter and Easton 2011; Carter and Rogers 2008), which suggested that programs that address all three dimensions would be "best", and intersections of two of the dimensions would be "better". It has to be noted that this kind of thinking does not follow the newly proposed ecologically-dominant logic (Montabon et al. 2016) and its proposed clear sequencing to first analyze environmental, then social, then economic viability, but instead operates more with a balancing motive in which some companies might still prioritize economic motives to the detriment to one or two of the other dimensions. Nevertheless, the case results show that the businesses go beyond that "better" notion by compensating for the missing dimensions, i.e. from double bottom line outputs to triple bottom line outcomes. Again, it is important to note that the social businesses can only do so because they simultaneously and 
consciously design their physical chain (for outputs) and financial and information support chains (for outcomes) in line with TBL design parameters.

\section{[Please insert Figure 6 about here]}

The first illustration in Figure 6 is EPRO. In its "social product model" the business case is profitable (economic output), the energy is renewable (ecological output) and the product can be used as additional light for homework, fostering education and reducing health issues due to cooking with charcoal (social output). As an illustration, EPROs business plan regarding the latter says: "The consequences of fuel poverty are dramatic. Harmful emissions of carbon monoxide and micro particles linked to traditional cooking methods cause annual 4 million premature deaths worldwide".

The second example is CHIFA. In its "auxiliary financial chain model" the business case is profitable (economic output) and there is a health benefit of CHIFA's natural meat (social output), but it is only the additional waste management that gives it a positive environmental outcome and thereby brings it to TBL sustainability. As interviewee $\mathrm{C}$ at CHIFA explained: "For instance, to be environmentally conscious as an organization, as a social business, we have to deal, to collaborate, with organizations that work with the environment and agriculture. For instance, the waste of the chicken, we have to take it to other organizations in the community that do agroecology or agriculture."

The third example is COSMO. In its "positive externalities model" it provides a competitive product to generate profit (economic output), and it does not provide a more social output than its competitors (cosmetics to be used in another country). Instead, it creates positive social externalities in terms of income for underprivileged women (social outcome). At the same time, it takes care that there is excellent waste management (castor meal to be used as fertilizer or 
Accepted version status March 2017; Journal of Business Logistics (JBL)

fuel) to address the environmental dimension (environmental outcome). The following excerpt from COSMO's investor summary highlights the social side: "The women in [...] the area where [COSMO] sources castor oil, often suffer from abusive husbands and poor schooling for their children that give out certificates despite illiteracy. From interviews, [COSMO] understands that they would rather gain access to healthcare and clean water by earning an income instead of having to physically fight with men to get free water". And, concerning the environmental side: "Farming of castor oil will mitigate Haiti's deforestation by using marginal land, tackle soil erosion challenges and reduce global warming because castor beans act as a sink for carbon dioxide".

The fourth example is CLEAPRO. It also covers all three dimensions via outputs (physical chain) directly. Its products are profitable (economic output) and there is direct improvement of hygiene (social output). Illustrative of that health aspect is the following from CLEAPRO's business plan: "Haiti bears a very high burden of disease, which contributes to infant and child mortality - which is the worst in Latin America and the Caribbean. The disease burden can be directly related to low levels of water and sanitation coverage as well as poor household and personal hygiene practices." Although the products as such are not more environmentally friendly than those of competitors, CLEAPRO ultimately achieves TBL sustainability by having customers bring their own packaging, thus avoiding waste (environmental output). As interviewee D at CLEAPRO stated: "In terms of environmental, people use less plastic bottles by buying our product this way, so less trash in the street. Social impact, people have access to cleaning products that improve their environment and their lives. Economic impact, all of our point of sales take 30\% profit on what they sell, so [...] I think in a way, all these 3 things are very achievable and have been achieved so far." 


\section{TOWARD A THEORY OF SUSTAINABLE SUPPLY CHAIN DESIGN (SSCD)}

As this research elaborates the theory of the supply chain, the way the analysis and results have been structured follows Wacker's (1998) four components of a theory. This also corresponds to Whetten's (1989) recommendations to convey a theoretical contribution in terms of the what, how, domain and why. At the same time, following the criteria of Fawcett and Waller (2011), what makes a theoretical contribution is that it is both influential and interesting. Influential, as the insights on how to think differently about the domain, the supply chain design parameters and structure can help truly rethink global supply chains. And interesting, as how to actually design TBL sustainable supply chains that address a practical challenge and field of global societal, managerial and academic concern. The overall research findings toward a theory of sustainable supply chain design (SSCD) are summarized in Figure 7.

\section{[Please insert Figure 7 about here]}

\section{Variables of SSCD}

The variables (component 1), i.e. the design parameters, the structural elements and the performance variables, are elaborated toward a theory of sustainable supply chain design. Regarding the design parameters and structural elements, the cases analyzed highlighted that design parameters from all three legs of the TBL are in scope right from the beginning and the design elements comprise both physical material and support flows.

Thus, the first proposition:

Proposition 1: SSCD includes economic, environmental and social design parameters and physical material and support flows. 
Accepted version status March 2017; Journal of Business Logistics (JBL)

In terms of testability, this first proposition is more about exploring variables in the future. While a starting point, further work on operationalization of the constructs for future testing is needed.

Related to the design parameter variables, this research highlighted the differentiation of outputs versus outcomes. Most previous research has implicitly centered on outputs as the result of the physical material flows. In contrast to that, the social businesses designed both - economic, environmental and social outputs and outcomes into their supply chains. Whereas outputs correspond to the products moving along the physical chain and the economic, environmental and social effects directly connected to that flow, outcomes correspond to TBL results achieved via support chains in the design. This goes beyond previous research on sustainable products (Seuring, 2011). Thus, the second proposition is that:

Proposition 2: Within an SSCD economic, environmental and social design parameters can be operationalized into intended outputs and outcomes.

In terms of testability, replication studies would be helpful to test this differentiation's broader applicability as well as further detail construct operationalization.

It is also important to note that, counter to the theory of the supply chain (Carter, et al. 2015), the physical, financial and information support chains do not always flow in the same way. In contrast to common assumptions (i.e. that financial flows come after the others), the financial support chain is initiated before the physical material flows and follows a pattern that supports the business versus the supply chain. Also, considering where the financial resources flow, in cases such as CHIFA, there is no physical material flow required to meet the sustainable objectives; instead, it is to meet sustainable outcomes, meaning that the support chains have to take a high priority in the scheme of the business in order to deliver the appropriate value to the appropriate place. Thus: 
Proposition 3: Within an SSCD physical material and support flows can take multiple flow directions.

In terms of testability, replication studies that apply the same research design that was followed here, but to other contexts such as country-wise and industry-wise, are suggested. This could be tested by analyzing a broader sample regarding the physical material, financial and information flows and their respective directions.

\section{The domain of SSCD}

Concerning the domain (component 2), in the cases the intended sustainability objectives of a broad stakeholder base were considered first and then the conscious design of a sustainable supply chain, configuration of all three physical, financial and information chains occurred. In contrast to most of the extant SSCM literature, the design parameters stem from all three TBL dimensions. The stakeholders taken into account before the design stage determine the design parameters, as their needs determine which sustainability criteria are in focus and how the model may be structured. Thus, one implication for further research in sustainable supply chain design is to consider other types of supply chains and identify and map all of the relevant stakeholders related to the flow of physical materials, finance and information with the intent of understanding how to deliver sustainable TBL value. Thereby, this research supports ideas put forth by Pagell and Wu $(2009,39)$ where "Reconceptualizing the chain to include these nontraditional members may be a key component of SSCM". What creates value for these stakeholders becomes the intended chain output and/or outcome. Thus:

Proposition 4: SSCD's domain includes economic, environmental and social stakeholders.

In terms of testability, this fourth proposition is about defining the realm to which a theory of SSCD applies. For future research, this is mainly an aspect to take into account in research 
design. But how to operationalize it empirically and how to approach it methodologically may be refined and broadened as well.

\section{Relationships and predictions in SSCD}

Concerning the variable relationships and predictions (components 3 and 4), TBL design parameters are in scope during the design phase, and social businesses design both the "primary" and the "supplemental" chains simultaneously. Using the cases as innovative examples, the research here suggests planning backwards, i.e. to start with TBL design parameters and then design physical, financial and information support chains for their attainment. This adds to the theory of the supply chain (Carter et al., 2015) in the sense that the physical material flows and the supplemental chains that support those flows both are instrumental when supply chains are designed with intent or purpose to meet other non-economic goals such as environmental and social goals. Thus:

Proposition 5: Within a SSCD physical material and support flows are purposefully combined to deliver TBL outputs and/or outcomes.

In terms of testability, this is a very specific structural variables-outcome/output variables relationship. Here, further research could investigate the sequential relationship between the purpose (operationalized in outputs and outcomes) and how the structural elements are then chosen and combined.

Also, building on the findings summarized in Figures 6 and 7 a key insight is that TBL sustainability can be designed in, even if the outputs of the model do not yet cover all three dimensions. Then, this still can be remedied by building in additional mechanisms to compensate the missing dimension towards a positive outcome in that dimension. Thus:

Proposition 6: Within a SSCD support chains can be designed to achieve sustainable outcomes, even if sustainable outputs cannot be delivered directly. 
Accepted version status March 2017; Journal of Business Logistics (JBL)

In terms of testability, this concerns the relationship between the TBL design parameters outputs and outcomes as substitutes. Apart from the examples provided earlier and also discussed in the practical implications, a broader scale study on such substitution in both start-ups and established firms would be helpful to understand the current prevalence and the potential use of such substitution, as well as contingencies for it. Future research might investigate how TBL outcomes can be designed into supply chains, even if outputs do not consider all three dimensions, and also assess how TBL outcomes can be retrofitted into existing supply chains.

Finally, YSB clearly stated that three of the cases, i.e. EPRO, CHIFA and COSMO, are representative of three configurations, which cover YSB's portfolio of social businesses. In two of these, a financial support chain plays a central role. The context of social businesses in Haiti highlighted the important role of support chains, as the constraints under which supply chain design takes place makes this role especially pronounced. The three configurations "social product model", "auxiliary financial chain model" and "positive externalities model". Thus:

Proposition 7: Within an SSCD there are basic configurations of structural combinations to deliver TBL outputs and/or outcomes.

In terms of testability, similar to our suggestions for proposition 2, replication studies would be helpful to test whether these remain three of the most generic SSCD configurations or if other more typical configurations emerge (in different contexts).

\section{Refining the definition of SSCD: Prioritizing the design parameters}

While focused on bringing TBL sustainability into supply chains, this research did not more specifically focus on how the design parameters relate to each other, i.e., should the parameters be balanced or in some way prioritized? Going forward, future research could investigate this aspect by taking into account recent work on the anthropocentric versus ecocentric perspective (Borland et al. 2016) or the ecologically dominant logic mentioned earlier (Montabon et al. 2016). 
In the spirit of that latter new paradigm, a combination of the output versus outcome differentiation with the sequencing approach by Montabon et al. (2016) is suggested. Companies should check whether what they intend to do leads to environmentally sustainable outputs. If yes, companies should proceed, otherwise they should check whether through design of support chains they might mitigate or overcompensate detrimental effects. If that succeeds, companies would proceed to the same assessment in social terms, first outputs, then outcomes (via support chains). Last, economic viability would be assessed in terms of outputs and outcomes. Through this we see an interesting way to combine an upcoming paradigm shift that provides insights on how the design parameters should be handled with what we could extract in this research in terms of outputs versus outcomes and the structural elements to attain those.

In line with these considerations, the earlier-given definition of SSCD is refined here for future research to include such a sequencing: SSCD is the design of physical material, information and capital flows as well as cooperation among companies along the supply chain based on sequentially analyzing environmental, social and economic viability (in terms of outputs and outcomes), which is derived from economic, environmental and social stakeholder requirements. Viability at each stage of analysis (environmental, then social, then economic) must at least be ensured in outcomes, e.g. by incorporating a support chain; if that is not feasible, the analysis does not proceed and the design is not viable.

\section{Further research suggestions}

Those that perform the design of the sustainable supply chain, i.e. the social entrepreneurs, determine how all three sets of constraints (economic, social and environmental) can be met with a matching configuration. This highlights how social entrepreneurs excel at recognizing and taking advantage of opportunities, without being limited by the resources currently available (Dees 1998), 
to deliver the social value of their mission (Sullivan Mort et al. 2003). The social entrepreneurs play a significant role with a mission-driven focus; the relationships with the stakeholders are crucial in early design stages, similar to the recent finding that individual actors' commitment plays a key role in environmental supply chain management (Wichmann et al. 2015). Bringing in the role of the social entrepreneur and broad stakeholder base, this research corresponds to, but extends, earlier findings on preconditions for optimization of the economic and environmental dimensions being a "committed workforce [...] highly motivated to work for these companies for non-economic reasons" and in the face of the constraints "[... ] rather than using cost and resource constraints to motivate cost-neutral solutions as an excuse for inaction, they use these constraints to motivate cost-neutral solutions and innovation $[\ldots]$ and help create supply chain practices that clearly differ from industry norms" (Wu and Pagell 2011, 583).

Finally, as an outlook on how the design might be further differentiated, Carter et al.'s (2015) suggestion to differentiate which parts of the flows are controlled internally by the focal firm versus outsourced could be further investigated. In the context of sustainability, an intermediary stakeholder such as YSB can be instrumental for providing certain information to the focal business, or in imagining a scenario in which an NGO can act as a partner for outsourced sustainability certification. Apart from the make or buy dimension, the geography of where the activity is performed also could be taken into account.

Insights from international business on where certain parts of the chain create most value could be taken into account (e.g. Mudambi 2008), but be newly interpreted to include value creation beyond economic terms, or in other words including environmental and social outputs and outcomes. For example, at the intersection to the reshoring phenomenon, some European companies are redesigning their supply chains by bringing certain nodes in the network back to or 
Accepted version status March 2017; Journal of Business Logistics (JBL)

closer to home markets (e.g. Foerstl et al. 2016). In effect, that is a form of supply chain re-design. From a sustainability point of view, this opens interesting opportunities, e.g. to reduce the transportation carbon footprint, improve energy efficiency and/or labor law adherence, etc. (e.g. Ashby 2016).

\section{Implications for practice}

There are a number of managerial implications based on the propositions put forward in an effort to elaborate a theory of sustainable supply chain design (SSCD). First, considering the scope of design efforts, there is a tremendous opportunity to begin with a blank slate and identify the relevant stakeholders and define what "TBL value" in terms of outputs and outcomes implies for them. As the cases illustrated, there is a way to ensure that a model is set up to succeed according to TBL design parameters from the start, rather than to design for economic output, and then try to improve later.

Second, when the definition of the intended outputs and outcomes is clear, the actual design benefits not only from designing the physical chain, but also financial and information support chains. This can provide a fresh take on well-established industry models. The three configurations shown here might serve as inspiration for practice. If outputs cannot meet TBL criteria, this can still be remedied to achieve TBL outcomes by introducing support chains. An example would be the airline business, which conventionally might be considered inherently unsustainable on the environmental side $\left(\mathrm{CO}_{2}\right.$ emissions).

The models studied here teach a different lesson: Even if your company's output will not be sustainable, your outcome still may be. For example, this could be offsetting emissions by investing in $\mathrm{CO}_{2}$ compensation schemes (e.g. Atmosfair), i.e. a financial support chain to another institution, for achieving a neutral or even positive environmental outcome. While this 
environmental example highlights how outputs and outcomes can be substitutes, from a normative point of view it should be mentioned that companies should aim to achieve environmental, social and economic sustainability considering all technological progress via outputs first, and resort to compensate via outcomes only if there is no option to make the output sustainable. So, as long as airlines need kerosene for their planes, offsetting $\mathrm{CO}_{2}$ would be a way to achieve environmentally sustainable outcomes. But taking the automotive industry as an example, technological breakthroughs at hand would actually allow a direct move to environmentally sustainable outputs, e.g. electronic cars using fully regenerative energy (e.g. solar). In other words, ways to indirectly compensate via outcomes should not become an excuse for not improving outputs directly.

Third, these findings are also interesting to policy makers because economic development funds could be more closely connected to business plans' potential to create TBL outputs and outcomes as well as be subject to more scrutiny of the involved physical and support chains. Particularly, the model type 2, "auxiliary financial chain model”, is of further interest here to avoid unintended consequences by more traditional means of catastrophe or development aid. YSB gave several examples of how donations actually had a detrimental effect on the development of a permanent provision of a social good or service in the market. One of them was in the context of EPRO, when after a natural catastrophe cooking stoves were handed out for free. This actually devastated the local market for businesses like EPRO and - once the donations stopped - left access to those goods worse than before. Therefore, model type 2 is also called an "exit strategy for aid"at YSB. This is meant as a strategy to help NGOs and donation-based organizations exit a scenario where a population relies continuously on external financial aid by putting a long-term solution that sustains itself in place instead. The example here being that instead of giving out free 
Accepted version status March 2017; Journal of Business Logistics (JBL)

solar lamps, but only as long as the aid budget permits, a local social business is able to continuously supply the market at affordable prices.

\section{CONCLUSIONS}

This research set out to address these two research questions: 1. How are supply chain structures of sustainable businesses designed to deliver on TBL objectives? 2. How do the different configurations support sustainability?

Regarding the "design", this research puts forward that economic, environmental and social stakeholders, output and outcome design parameters and both physical and support chains were identified for sustainable supply chain design. Regarding the "support of sustainability", this study offered a more detailed view about how design parameters are operationalized as TBL outputs versus outcomes.

From a conceptual contribution point of view, this paper particularly aimed at "revision" (Fawcett et al. 2014, 5), as it proposes changes to the theory of the supply chain, i.e. to extend the domain and variables, toward a theory of sustainable supply chain design. The social businesses in Haiti offered a unique context to better understand how to achieve sustainable supply chain configurations that cover all three sustainability dimensions and offered three configurations. This research may thus become a starting point for more SSCM research on social businesses versus research on larger firms such as multinational corporations that reconsider their own models rather slowly and gradually.

With regard to limitations, the results here are derived from four cases within one social business investor company portfolio within one specific country. Although the context of Haiti has a number of advantages to study the research questions in focus in an extreme setting characterized by severe resource scarcity, future research should see whether the identified configurations are 
similar or different in other contexts. While Haiti was a rather specific context, meant to show pronounced designs in the face of severe constraints, this is an interesting implication for mature markets as well, though the support chains may take different forms.

For example, while microfinance institutions may often play an important part for emerging markets, for mature markets other financial flows such as crowd funding could be deliberately designed into the chain configurations if that creates TBL outputs and outcomes for stakeholders. Nevertheless, based on the context studied here, the cases served to illustrate how the distinction of physical and support chains only put forward recently as a theory of the supply chain (Carter et al. 2015) can be elaborated toward a theory of SSCD. In contrast to most of the existing supply chain design literature, the implication here is to extend design to not only design of the physical chain, but also the support chains.

Expanding the horizon of supply chain design literature in general beyond a rather narrow focus on physical chains as the primary ones is also worthwhile considering the context of service companies and asking whether the "support" chains of financial and information flows may actually be their primary ones. In services scenarios it is conceivable that, instead, the physical chain is just supporting (e.g. in an insurance company where the physical documents are just a formality after customer value has been delivered in terms of consulting and matching insurance and profile). With trends such as servitization and digitization, the deliberate design of all three (physical, financial and information) chains is thus bound to become increasingly important.

In summary, the elaboration of the domain, variables and connection of the three basic configurations with the theory of the supply chain (Carter et al. 2015) toward a theory of SSCD offers new thinking for research and practice to leave behind retrofitting supply chains to be less harmful, and instead start creating and designing them for true sustainability. 


\section{REFERENCES}

Amit, R., and Zott, C. 2010. "Business model design: an activity system perspective." Long Range Planning 43(2/3):216-26.

Amit, R., and Zott, C. 2001. "Value creation in e-business." Strategic Management Journal 22(6/7):493-520.

Ashby, A. 2016. "From global to local: reshoring for sustainability." Operations Management Research 9(3-4): 75-88.

Beamon, B.M. 2005. "Environmental and sustainability ethics in supply chain management." Science and Engineering Ethics 11(2):221-234.

Beamon, B.M. 1998. "Supply chain design and analysis: Models and methods." International Journal of Production Economics 55(3):281-294.

Bode, C., and Wagner, S.M. 2015. "Structural Drivers of Upstream Supply Chain Complexity and the Frequency of Supply Chain Disruptions." Journal of Operations Management 36:21528.

Boons, F. and Luedeke-Freund, F. 2013. "Business models for sustainable innovation: state-ofthe-art and steps toward a research agenda." Journal of Cleaner Production 45 (April):919.

Borland, H., Ambrosini, V., Lindgreen, A. and Vanhamme, J. (2016). Building theory at the intersection of ecological sustainability and strategic management. Journal of Business Ethics, 135, 293-307.

Carter, C.R., and Easton, L. 2011. "Sustainable supply chain management: evolution and future directions." International Journal of Physical Distribution \& Logistics Management 41(1):46-62.

Carter, C.R., and Rogers, D.S. 2008. "A framework of sustainable supply chain management: moving toward new theory." International Journal of Physical Distribution \& Logistics Management 38(5):360-387.

Carter, C.R., Rogers, D.S., and Choi, T.Y. 2015. "Toward the Theory of the Supply Chain." Journal of Supply Chain Management 51(2):89-97.

Chaabane, A., Ramudhin, A., and Paquet, M. 2012. "Design of sustainable supply chains under the emission trading scheme." International Journal of Production Economics 20(61):772729.

Chaabane, A., Ramudhin, A., and Paquet, M. 2011. "Designing supply chains with sustainability considerations." Production Planning \& Control: The Management of Operations 22(8):727-741.Chen L, Olhager J, and Tang, O. 2014. "Manufacturing facility location and sustainability: a literature review and research agenda." International Journal of Production Economics 149:154-163.

Christmann, P. 2000. "Effects of "best practices" of environmental management on cost advantage: The role of complementary assets." Academy of Management Journal 43(4):663-680.

Cohen, M.A., and Lee, H.L. 1989. "Resource deployment analysis of global manufacturing and distribution networks." Journal of Manufacturing and Operations Management 2(2):81104.

Creswell, J.W. 2014. A concise introduction to mixed methods research. New York: Sage Publications. 
Cruz, J.M., and Matsypura, D. 2009. "Supply chain networks with corporate social responsibility through integrated environmental decision-making." International Journal of Production Research 47(3):621-648.

Dees, J.G. 1998. “Enterprising nonprofits.” Harvard Business Review 76(1):55-66.

Dubois, A., and Gibbert, M. 2010. "From complexity to transparency: Managing the interplay between theory, method and empirical phenomena in IMM case studies." Industrial Marketing Management 39(1):129-136.

Durach, C.F., Wieland, A., and Machuca, J.A.D. 2015. "Antecedents and Dimensions of Supply Chain Robustness: A Systematic Literature Review." International Journal of Physical Distribution \& Logistics Management 45(1/2):118-37.

Eisenhardt, K.M. 1989. "Building theories from case study research." Academy of Management Review 14(4):532-550.

Elkington, J. 1998. Cannibals with forks. Gabriola Island: New Society Publishers.

Ellram, L.M. 1996. "The use of the case study method in logistics research." Journal of Business Logistics 17(2):93-138.

Eskandarpour, M., Dejax, P., Miemczyk, J., and Péton, O. 2015. "Sustainable supply chain network design: An optimization-oriented review." Omega 54:11-32.

European Commission (2015). "Paris Agreement." http://ec.europa.eu/clima/policies/international/negotiations/paris/index_en.htm.

Fawcett, S.E., and Waller, M.A. 2015. "Editorial: Designing the Supply Chain for Success at the Bottom of the Pyramid." Journal of Business Logistics 36(3):233-239.

Fawcett, S.E., and Waller, M.A. 2011. "Making Sense Out of Chaos: Why Theory is Relevant to Supply Chain Research.” Journal of Business Logistics 32(1):1-5.

Fawcett, S.E., Waller, M.A., Miller, J.W., Schwieterman, M.A., Hazen, B.T., and Overstreet, R.E. 2014. "A Trail Guide to Publishing Success: Tips on Writing Influential Conceptual, Qualitative, and Survey Research.” Journal of Business Logistics 35(1):1-16.

Flyvbjerg, B. 2006. "Five Misunderstandings About Case-Study Research." Qualitative Inquiry 12(2):219-245.

Foerstl, K., Kirchoff, J., and Bals, L. 2016. "Reshoring and Insourcing: Drivers and Future Research Directions." International Journal of Physical Distribution and Logistics Management 46(5):492-515.

Ford, D. 1990. "Part VII: Networks." In Understanding business markets: Interaction, relationships, and networks, edited by D. Ford. London: Academic Press.

Gibbert, M., Ruigrok, W., and Wicki, B. 2008. "What passes as a rigorous case study?" Strategic Management Journal 29(13):1465-1474.

Grabenwarter, U., and Liechtenstein, H. 2011. "In search of gamma-an unconventional perspective on impact investing." IESE Business School, http://iese.edu/research/pdfs/ESTUDIO-158E.pdf.

Handfield, R.B., Walton, S.V., Seegers, L.K., and Melnyk, S.A. 1997. "'Green' value chain practices in the furniture industry." Journal of Operations Management 15(4):293-315.

Harris, I., Naim, M., Palmer, A., Potter, A., and Mumford, C. 2011. "Assessing the impact of cost optimization based on infrastructure modeling on $\mathrm{CO}_{2}$ emissions." International Journal of Production Economics 131(1):313-321.

Hassini, E., Surti, C., and Searcy, C. 2012. "A literature review and a case study of sustainable supply chains with a focus on metrics." International Journal of Production Economics 140(1):69-82. 
Howard-Grenville, J., Buckle, S.J., Hoskins, B.J., and George, G. 2014. "Climate change and management." Academy of Management Journal 57 (3): 615-623.

Hugo, A., and Pistikopoulos, E.N. 2005. "Environmentally conscious long-range planning and design of supply chain networks." Journal of Cleaner Production 13(15):1471-1491.

Hussain, N., Rigoni, U., and Orij, R. P. 2016. "Corporate Governance and Sustainability Performance: Analysis of Triple Bottom Line Performance." Journal of Business Ethics, 122.

Ishii, K., Takahashi, K., and Muramatsu, R. 1988. "Integrated production, inventory and distribution systems." International Journal of Production Research 26(3):473-482.

Jick, T.D. 1979. "Mixing qualitative and quantitative methods: Triangulation in action." Administrative Science Quarterly 24(4):602-611.

Jin, M., Granda-Marulanda, N.A., and Down, I. 2014. "The impact of carbon policies on supply chain design and logistics of a major retailer." Journal of Cleaner Production 85:453-461.

Ketokivi, M., and Choi, T. 2014. "The renaissance of case research as a scientific method". Journal of Operations Management 32(5):232-240.

Krikke H, Bloemhof-Ruwaard J., and van Wassenhove L.N. 2003. "Concurrent product and closed-loop supply chain design with an application to refrigerators." International Journal of Production Research 41(16):3689-3719.

Lee, J.L., Mitchell, T.R., and Sablynski, C.J. 1999. "Qualitative Research in Organizational and Vocational Psychology, 1979-1999." Journal of Vocational Behavior 55(2):161-187.

Lee, H.L., Padmanabhan, V., and Whang, S. 1997. "Information distortion in a supply chain: The bullwhip effect." Management Science 43(4):546-558.

Linton, J.D., Klassen, R., and Jayaraman, V. 2007. "Sustainable supply chains: An introduction." Journal of Operations Management 25(6):1075-1082.

Lyons, T. 2013. The Role of Social Entrepreneurship in Sustainable Business. http://www.triplepundit.com/2013/09/role-social-entrepreneurship-sustainable-business.

Mallidis, I., Dekker, R., and Vlachos, D. 2012. "The impact of greening on supply chain network design and cost: a case for a developing region." Journal of Transport Geography 22(1):118-128.

Mallidis, I., Vlachos, D., Iakovou, E., and Dekker, R. 2014. "Design and planning for green global supply chains under periodic review replenishment policies." Transportation Research Part E: Logistics and Transportation Review 72(C):210-235.

Márquez, P.C., Reficco, E., and Berger, G. 2010. "Socially Inclusive Business: Engaging the Poor Through Market Initiatives in Iberoamerica." Harvard University, David Rockfeller Center for Latin American Studies and Inter-American Development Bank.

Matos, S., and Hall, J. 2007." Integrating sustainable development in the supply chain: the case of life cycle assessment in oil \& gas and agricultural biotechnology." Journal of Operations Management 25(6):1083-1102.

Matos, S., and Silvestre, B.S. 2013. "Managing stakeholder relations when developing sustainable business models: The case of the Brazilian energy sector." Journal of Cleaner Production 45(20):61-73.

Meixell, M.J., and Gargeya, V.B. 2005. "Global supply chain design: A literature review and critique." Transportation Research Part E: Logistics and Transportation Review 41(6):531-550. 
Melnyk, S.A., Sroufe, R.P., and Calantone, R. 2003. "Assessing the impact of environmental management systems on corporate and environmental performance." Journal of Operations Management 21(3):329-351.

Mena, C., Humphries, A., and Choi, T.Y. 2013. "Toward a theory of multi-tier supply chain management." Journal of Supply Chain Management 49(2):58-77.

Mentzer, J.T., DeWitt, W., Keebler, J.S., Min, S., Nix, N.W., Smith, C.D., and Zacharia, Z.G. 2001. "Defining supply chain management." Journal of Business Logistics 22(2):1-25.

Montabon, F., Pagell, M., and Wu, Z. 2016. "Making sustainability sustainable.” Journal of Supply Chain Management 52(2):11-27.

Mudambi, R. 2008. "Location, control and innovation in knowledge-intensive industries." Journal of economic Geography 8(5):699-725.

Neto, J.Q.F., Bloemhof-Ruwaard, J.M., Van Nunen, J.A.E.E., and van Heck, E. 2008. "Designing and evaluating sustainable logistics networks." International Journal of Production Economics 111(2):195-208.

Osterwalder, A., and Pigneur, Y. 2009. Business model generation: A handbook for visionaries, game changers, and challengers. Amsterdam: John Wiley \& Sons.

Pagell, M., and Shevchenko, A. 2014. "Why research in sustainable supply chain management should have no future." Journal of Supply Chain Management 50(1):44-55.

Pagell, M., and $\mathrm{Wu}, \mathrm{Z}$. 2009. "Building a more complete theory of sustainable supply chain management using case studies of 10 exemplars." Journal of Supply Chain Management 45(2):37-56.

Parmigiani, A., Klassen, R.D., and Russo, M.V. 2011. "Efficiency meets accountability: Performance implications of supply chain configuration, control and capabilities." Journal of Operations Management 29(3):212-223.

Pedrosa, A., Näslund, D., and Jasmand, C. 2012. "Logistics case study based research: towards higher quality", International Journal of Physical Distribution \& Logistics Management 42(3):275-295.

Porter, M., and Kramer, M.R. 2006. "Strategy and Society: The link between competitive advantage and corporate social responsibility." Harvard Business Review 84(12):42-56.

Prahalad, C.K. 2006. The Fortune at the Bottom of the Pyramid. India: Pearson Education.

Ramudhin, A., Chaabane, A., and Paquet, M. 2010. "Carbon market sensitive sustainable supply chain network design." International Journal of Management Science and Engineering Management 5(1):30-38.

Sarkis, J. 2006. Greening the Supply Chain. New York: Springer-Verlag.

Searcy, C. 2012. "Corporate sustainability performance measurement systems: A review and research agenda." Journal of Business Ethics 107(3): 239-253.

Seuring, S. 2013. "A review of modeling approaches for sustainable supply chain management." Decision Support Systems, 54(4):1513-1520.

Seuring, S. 2011. "Supply chain management for sustainable products-insights from research applying mixed methodologies." Business Strategy and the Environment 20(7):471-484.

Seuring, S., and Müller, M. 2008. "From a literature review to a conceptual framework for sustainable supply chain management." Journal of Cleaner Production 16(15):1699-1710.

Srivastava, S. 2007. "Green supply-chain management: a state-of-the-art literature review." International Journal of Management Reviews 9(1):53-80. 
Sullivan Mort, G., Weerawardena, J., and Carnegie, K. 2003. "Social entrepreneurship: Towards conceptualization." International Journal of Nonprofit and Voluntary Sector Marketing 8(1):76-88.

Sundarakani, B., de Souza, R., Goh, M., Wagner, S.M., and Manikandan, S. 2010. "Modeling carbon footprints across the supply chain." International Journal of Production Economics 128(1):43-50.

Tate, W., Bals, L. Forthcoming. "Achieving Shared Triple Bottom Line (TBL) Value Creation: Toward a Social Resource-Based View (SRBV)." Journal of Business Ethics.

Tate, W.L., Ellram, L.M., and Kirchoff, J.F. 2010. "Corporate social responsibility reports: a thematic analysis related to supply chain management." Journal of Supply Chain Management 46(1):19-44.

Thake, S. and Zadek, S. 1997. Practical people, noble causes. How to support community based social entrepreneurs. New Economics Foundation, London.

Towill, D.R., and del Vecchio, A. 1994. "The application of Filter Theory to the study of supply chain dynamics." Production Planning and Control 5(1):82-96.

Tzafestas, S, and Kapsiotis, G. 1994. "Coordinated control of manufacturing/ supply chains using multi-level techniques.” Computer Integrated Manufacturing Systems 7(3):206-212.

UN Water 2013. "World Water Day 2013: Facts and Figures." http://www.unwater.org/watercooperation-2013/water-cooperation/facts-and-figures/en.

Vachon, S., and Klassen, R.D. 2006. "Extending green practices across the supply chain: the impact of upstream and downstream integration." International Journal of Operations \& Production Management 26(7):795-821.

Varsei, M., and Polyakovskiy, S. 2016. "Sustainable supply chain network design: A case of the wine industry in Australia." Omega 66(Part B):236-247.

Varsei, M., Soosay, C., Fahimnia, B., and Sarkis, J. 2014. "Framing sustainability performance of supply chains with multidimensional indicators." Supply Chain Management: An International Journal 19(3):242-257.

Vidal, C.J., and Goetschalckx, M. 1997. "Strategic production-distribution models: A critical review with emphasis on global supply chain models." European Journal of Operational Research 98(1):1-18.

Wacker, J. G. 1998. "A definition of theory: research guidelines for different theory-building research methods in operations management." Journal of Operations Management 16(4):361-385.

Wang, F., Lai, X., and Shi, N. 2011. "A multi-objective optimization for green supply chain network design." Decision Support Systems 51(2):262-269.

Whetten, D.A. 1989. "What constitutes a theoretical contribution?" Academy of Management Review 14(4):490-495.

Wichmann, B.K., Carter, C.R., and Kaufmann, L. 2015. "How to Become Central in an Informal Social Network: An Investigation of the Antecedents to Network Centrality in an Environmental SCM Initiative.” Journal of Business Logistics 36(1):102-119.

Wieland, A., Handfield, R.B., and Durach, C.F. 2016. "Mapping the Landscape of Future Research Themes in Supply Chain Management." Journal of Business Logistics 37(3):205-212.

Wilson, F., and Post, J. E. 2013. "Business models for people, planet (\& profits): exploring the phenomena of social business, a market-based approach to social value creation." Small Business Economics 40(3): 715-737. 
Wood, D., Thornley, B., and Grace, K. 2013. "Institutional impact investing: practice and policy." Journal of Sustainable Finance \& Investment 3(2):75-94.

Wu, Z., and Pagell, M. 2011. "Balancing priorities: Decision-making in sustainable supply chain management." Journal of Operations Management 29(6):577-590.

Xia, Y., Zu, X., and Shi, C. 2015. "A profit-driven approach to building a 'people-responsible' supply chain." European Journal of Operational Research 241(2):348-360.

Yin, R.K. 2014. Case study research: Design and methods. New York: Sage Publications.

YSB 2014. Yunus Social Business Investors Brochure. 1-16.

Yunus, M., Moingeon, B., and Lehmann-Ortega, L. 2010. "Building social business models: lessons from the Grameen experience." Long range planning 43(2):308-325.

Zhu, Q., and Sarkis, J. 2004. "Relationships between operational practices and performance among early adopters of green supply chain management practices in Chinese manufacturing enterprises." Journal of Operations Management 22(3):265-289. 
Accepted version status March 2017; Journal of Business Logistics (JBL)

\section{FIGURES AND TABLES}

Figure 1: Theoretical framework based on the Theory of the Supply Chain (Carter et al. 2015) and review of the supply chain design literature

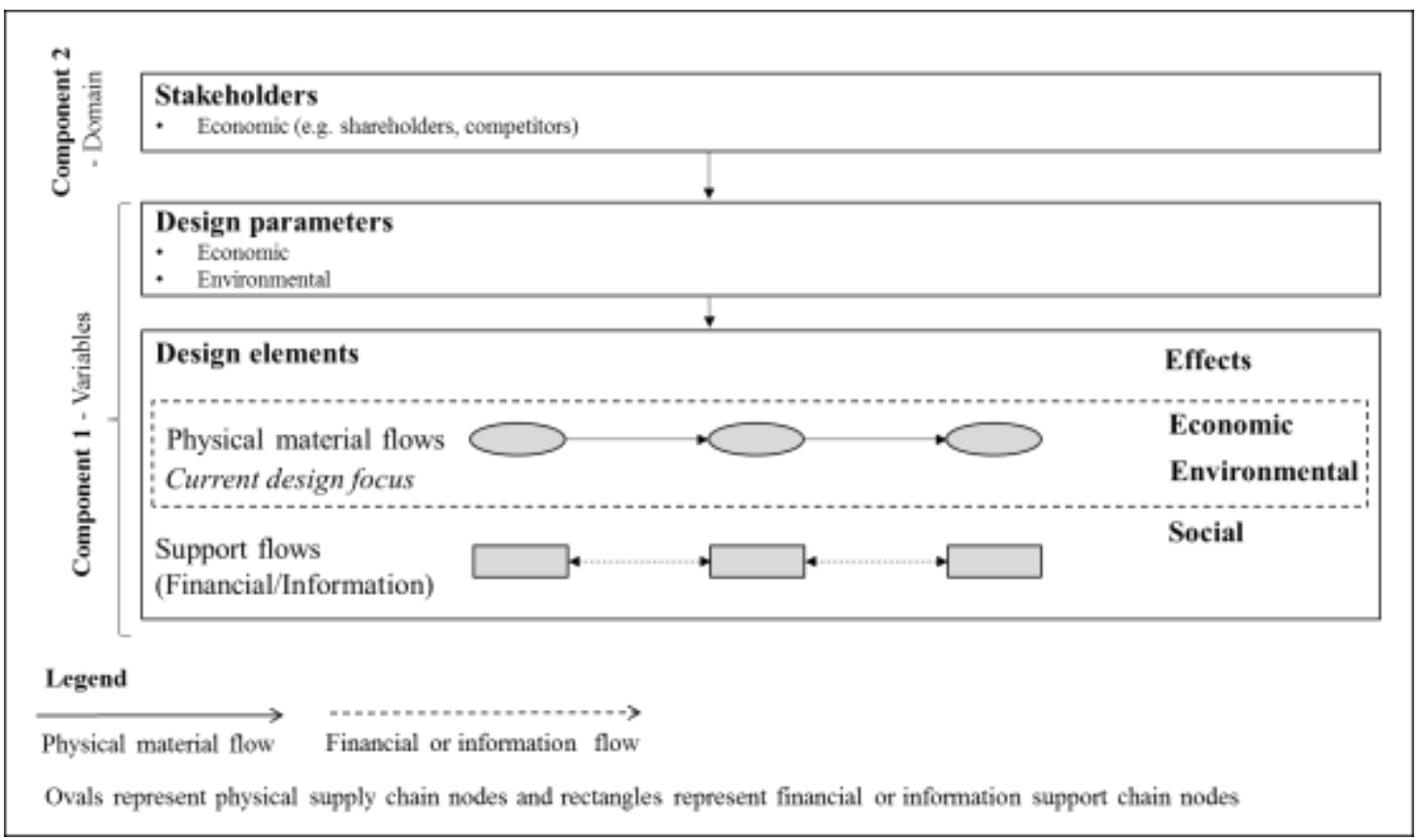

Figure 2: The physical and support supply chain, Carter et al. (2015), 92

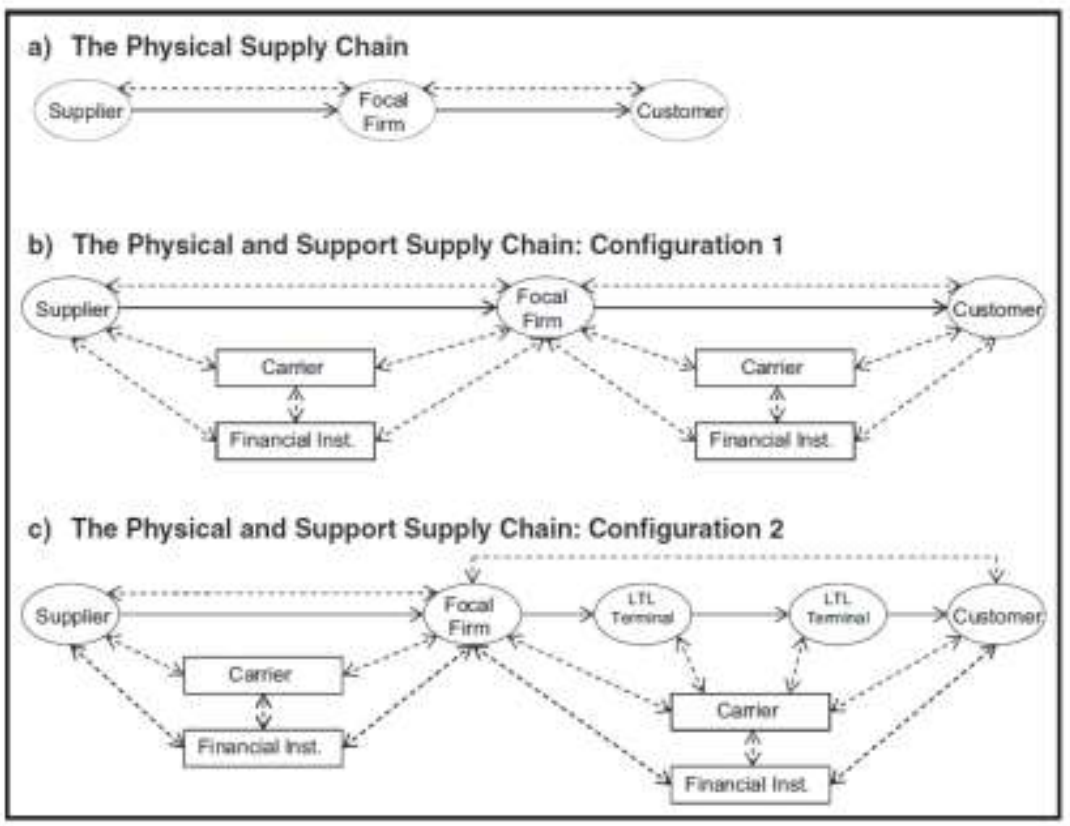

Note; Ovals represent physical supply chain nodes and rectangles represent support supply chain nodes. Solid lines represent the flow of product between physical nodes; dashed lines represent the flow of information and/or finance between physical and/or support nodes. 
Figure 3: Primary purposes of the three configurations by design

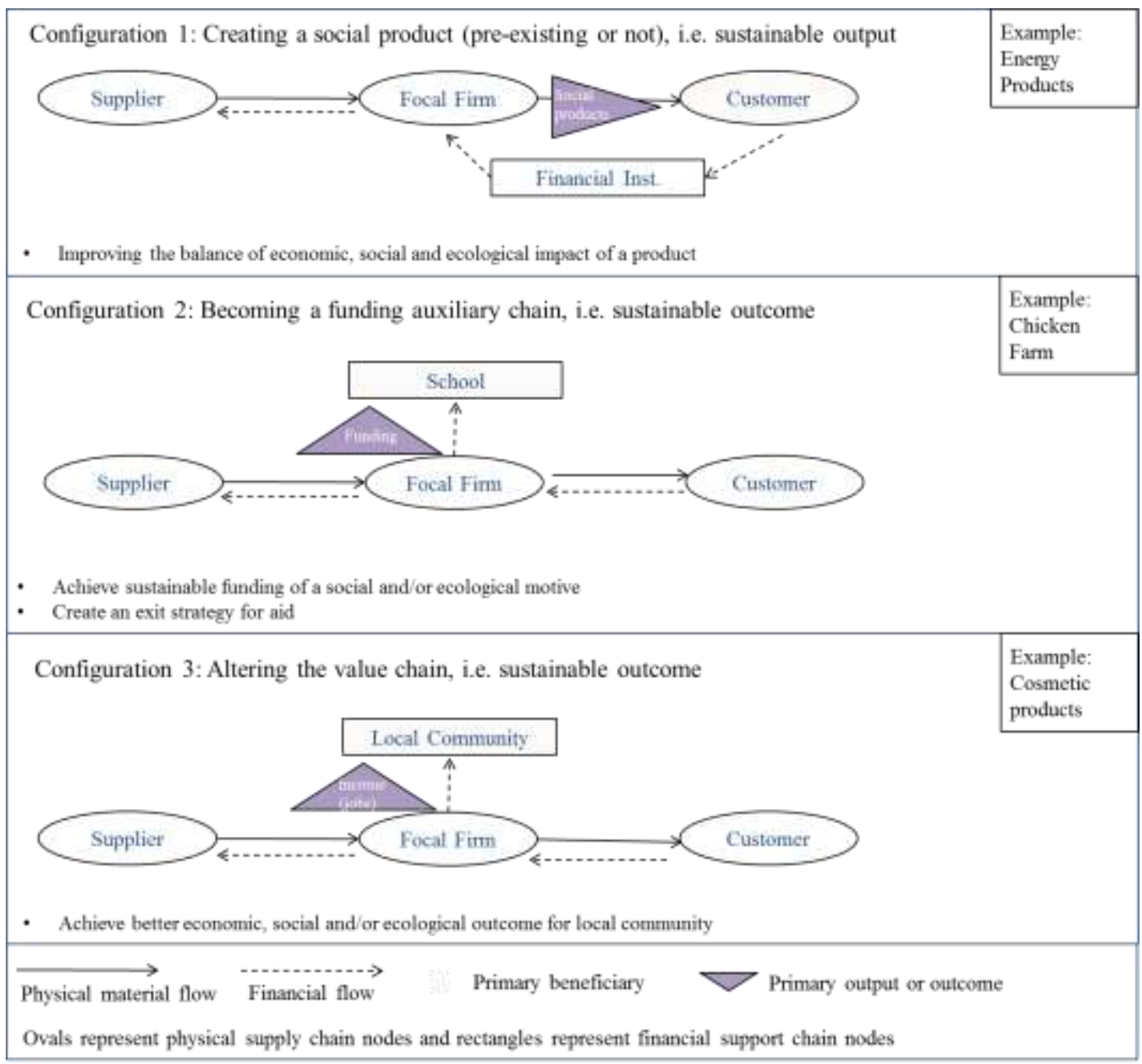


Figure 4: Financial support chains at EPRO

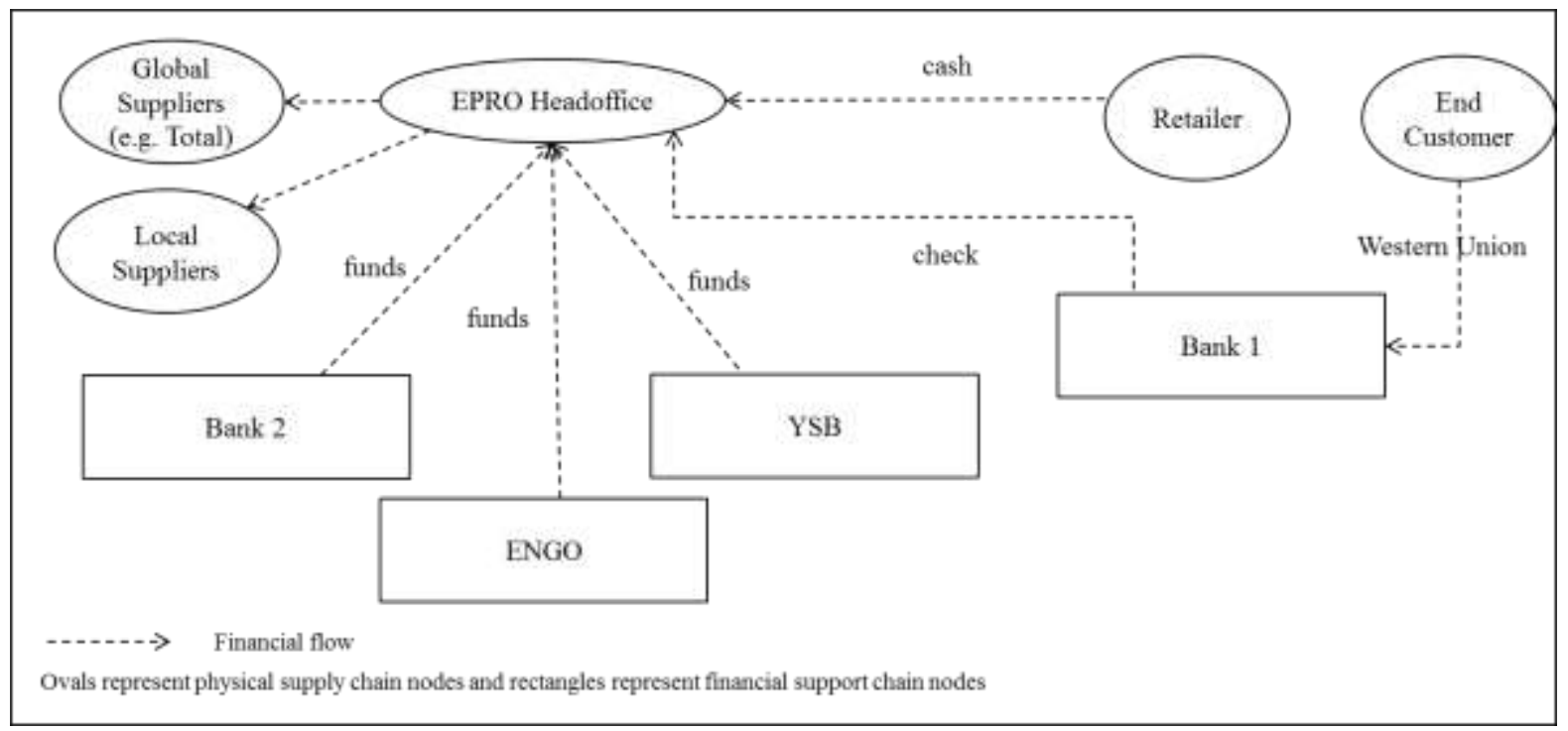

Figure 5: Financial support chains at CHIFA

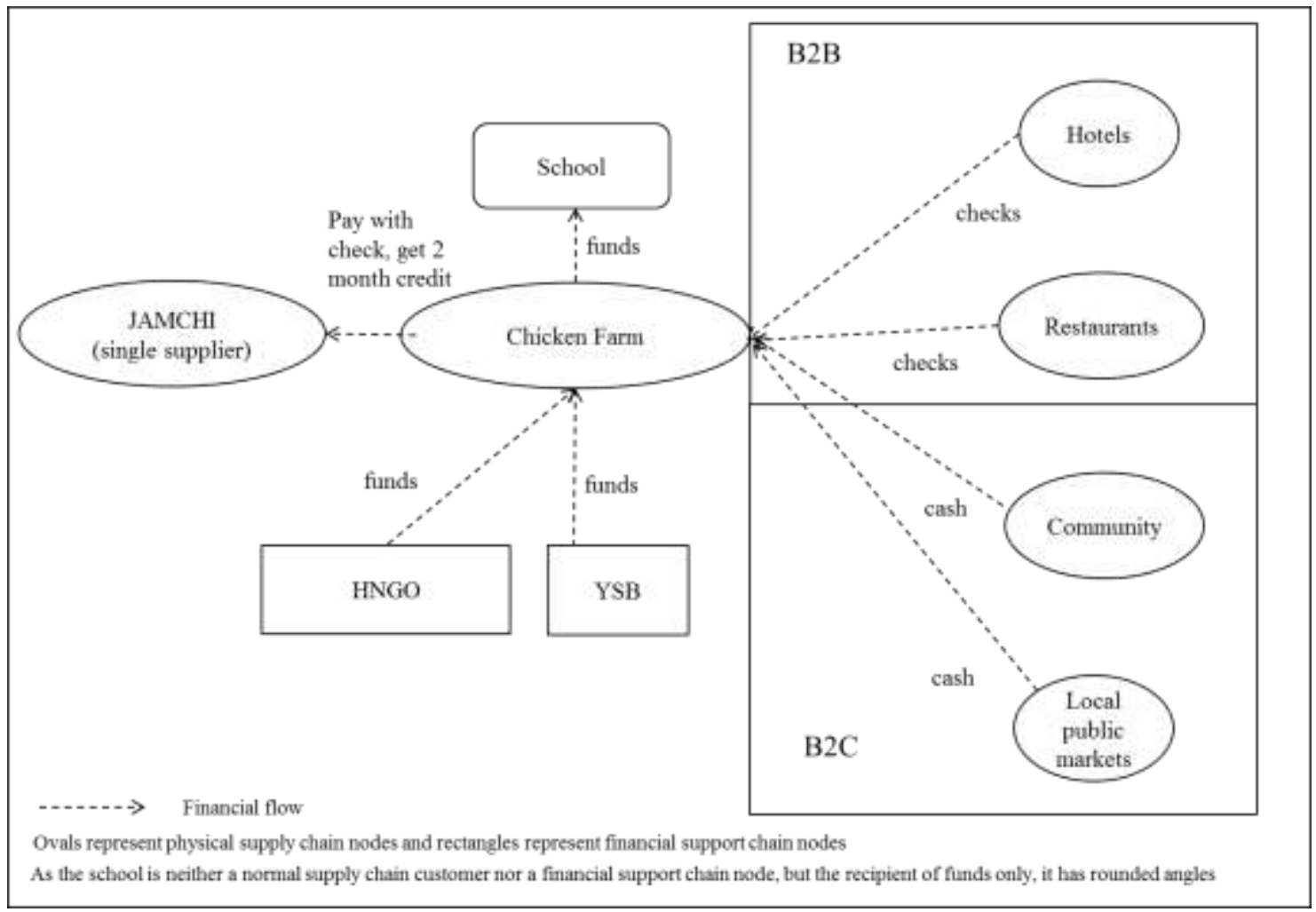


Figure 6: Getting from sustainable outputs to outcomes

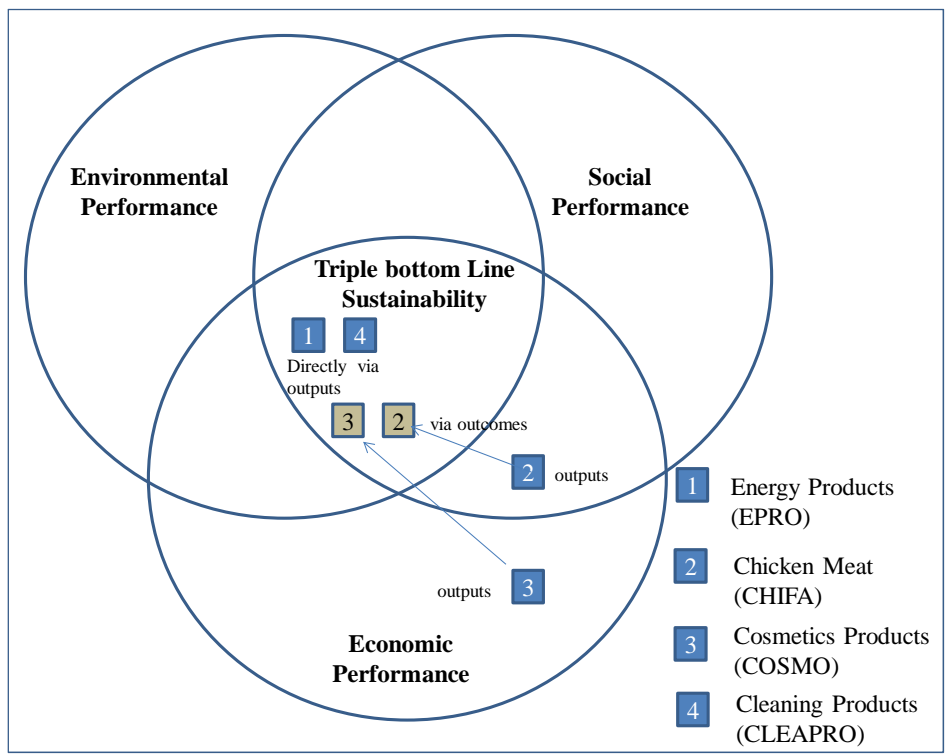

Figure 7: Elaborated theoretical framework

(P4)
(P1)


Table 1: Key definitions

\begin{tabular}{|l|l|}
\hline Authors & Definition of Supply Chain \\
\hline Mentzer et al. 2001,4-5 & $\begin{array}{l}\text { "A set of three or more entities (organizations or individuals) directly involved in } \\
\text { the upstream and downstream flows of products, services, finances and/or } \\
\text { information from a source to a customer" }\end{array}$ \\
\hline Carter et al. 2015,90 "a network, consisting of nodes and links" \\
\hline $\begin{array}{l}\text { Seuring and Müller 2008, } \\
1700\end{array}$ & $\begin{array}{l}\text { "The management [emphasis added] of material, information and capital flows as } \\
\text { well as cooperation among companies along the supply chain while taking goals } \\
\text { from all three dimensions of sustainable development, i.e., economic, environmental } \\
\text { and social, into account which are derived from customer and stakeholder } \\
\text { requirements" }\end{array}$ \\
\hline Varsei et al. (2014, 243) & $\begin{array}{l}\text { Supply Chain Design } \\
\text { "The design or reconfiguration of a supply chain is considered as a strategic goal } \\
\text { aiming at determining the number, location and capacities of manufacturing plants } \\
\text { and distribution centres, the set of suppliers to select and the effective flow of } \\
\text { material [emphasis added] throughout the supply chain". }\end{array}$ \\
\hline
\end{tabular}




\begin{tabular}{|c|c|c|}
\hline Interviewee & Interviewee Background & Business Design \\
\hline $\begin{array}{l}\text { YSB } \\
\text { Interviewee A } \\
\text { Haiti Country } \\
\text { Manager } \\
\text { Interviewee A }\end{array}$ & $\begin{array}{l}\text { The Haiti country manager had been in this } \\
\text { position for } 2 \text { years at the time of the interview, } \\
\text { in parallel to her role as head of investment. She } \\
\text { is originally trained as an industrial engineer } \\
\text { (Germany/France) and previously worked for an } \\
\text { international strategic management consultancy. } \\
\text { She also has prior NGO experience from related } \\
\text { positions in various countries before taking over } \\
\text { the position at YSB in Haiti. }\end{array}$ & $\begin{array}{l}\text { - YSB applies business approaches to the world of social development. It has developed an innovative } \\
\text { Incubator Fund methodology which bridges the gap between social businesses and social investors and } \\
\text { donors. While the Incubator searches, coaches and selects social businesses, the Fund provides debt and } \\
\text { equity financing to the businesses after a thorough due diligence process. While a traditional investor } \\
\text { invests for financial gain, a Social Investor invests to benefit society. } \\
\text { - At the time of the interviews, YSB were operating in several countries (e.g. Albania, Tunisia, Colombia) } \\
\text { and the Haiti Country Manager was the entry point to select the social business for further analysis }\end{array}$ \\
\hline $\begin{array}{l}\text { Case 1 "Energy } \\
\text { Products } \\
\text { (EPRO)" } \\
\text { Interviewee B } \\
\text { Founder }\end{array}$ & $\begin{array}{l}\text { The entrepreneur interviewed has been part of } \\
\text { this project for about two years. He is trained as } \\
\text { an agronomist and economist, then gathered } \\
\text { microfinance experience and later also got a } \\
\text { degree in energy. Before coming to Haiti, his } \\
\text { first social entrepreneurial experiences were in } \\
\text { Lebanon. }\end{array}$ & $\begin{array}{l}\text { - EPRO is a social business offering products for cooking and lighting, such as cooking stoves and solar } \\
\text { lamps. The cooking stoves are home appliances, but also can be used by smaller businesses such as } \\
\text { street vendors/small kitchens. Two types of solar lamps are offered and can be used either in homes or } \\
\text { for work. } \\
\text { - The customer base can quickly see the benefit of their investment. For example, for a street vendor of } \\
\text { food, making a switch from coal-based to EPRO's gas-based cooking stoves on average leads to a break- } \\
\text { even (including the payback of the IDE microfinance loan) of six months. } \\
\text { - Their business case highlights that the poorest households in Port-au-Prince have a payout for coal of } \\
\text { about } \$ 33 \text { per month, a third of their total budget. From an environmental perspective, deforestation is a } \\
\text { tremendous issue in Haiti and charcoal is - although illegal - largely coming from the last one-digit } \\
\text { percentage of native woods. The solar lamps also promote the transition to a renewable energy source. } \\
\text { On the social dimension, the products leave the customers with better economic prospects (so the } \\
\text { customers can accrue income for other purposes like education). With the solar lamps people have light } \\
\text { in the evening to work or study. Also, the gas stoves are better than charcoal as it relates to health } \\
\text { concerns. An illustrative extract from EPRO's business plan: "The consequences of fuel poverty are } \\
\text { dramatic. Harmful emissions of carbon monoxide and micro particles linked to traditional cooking } \\
\text { methods cause annual } 4 \text { million premature deaths worldwide [...]". }\end{array}$ \\
\hline $\begin{array}{l}\text { Case } 2 \\
\text { "Chicken Farm } \\
\text { (CHIFA)" } \\
\text { Interviewee C } \\
\text { Consultant }\end{array}$ & $\begin{array}{l}\text { The person interviewed is a consultant to a } \\
\text { number of social businesses and works for a } \\
\text { Haitian NGO (HNGO), a local partner of YSB. } \\
\text { Born in Haiti, he first worked there with the } \\
\text { Foundation for International Development } \\
\text { Assistance (FIDA). He then moved to the } \\
\text { United States, working in related areas for some } \\
\text { years, returning to Haiti in } 2011 \text {. He has an } \\
\text { MBA (United States) and a PhD in business } \\
\text { administration (Canada). }\end{array}$ & $\begin{array}{l}\text { - CHIFA is a social business producing chicken meat as a means to generate funding for a community } \\
\text { school. This is a social business model that has been applied a number of times by YSB. At the time of } \\
\text { the interviews, there were several chicken farms as well as a bakery operating in the same fashion. } \\
\text { Despite not being fully organic, CHIFA is not using any chemicals to raise the chicken. At the time of } \\
\text { the interviews, CHIFA was building a slaughterhouse to be able to sell the meat directly, and until then } \\
\text { was still relying on JAMCHI to buy the raised chicken back and slaughter them. } \\
\text { Regarding the economic side, the clear goal is to finance the school with the funds generated (and pay } \\
\text { the principal and interests back to YSB, as in all cases). Over the course of three years the model targets } \\
\text { coverage of 90-95\% of the school's costs. Regarding the environmental side, the avoidance of chemicals } \\
\text { in the chicken meat production as well as the use of the chicken waste as fertilizer for agriculture are } \\
\text { worth noting; also the overall supply chain is much shorter in comparison to the frozen imports, which } \\
\text { have to be transported and chilled over long distances, having a significant environmental benefit. }\end{array}$ \\
\hline
\end{tabular}




\begin{tabular}{|c|c|c|}
\hline $\begin{array}{l}\text { Case } 3 \\
\text { Cleaning } \\
\text { Products } \\
\text { (CLEAPRO) } \\
\text { Interviewee D } \\
\text { Founder }\end{array}$ & $\begin{array}{l}\text { The CFO interviewed has been part of the } \\
\text { business right from the beginning (during 2014). } \\
\text { Prior to that, until the year before, he was } \\
\text { involved in manufacturing at the parent } \\
\text { company. He has a background on Wall Street } \\
\text { and in a private equity fund in Haiti. He has an } \\
\text { MBA (United States). The main motivation for } \\
\text { the CFO resides in the belief that money can be } \\
\text { utilized to deliver the right products at the right } \\
\text { price to promote social good and the recognition } \\
\text { that most corporations only put aside a } \\
\text { minuscule proportion for social causes. }\end{array}$ & $\begin{array}{l}\text { - CLEAPRO is a social business offering cleaning products such as detergents, disinfectants and bleach. } \\
\text { Detergents are effective cleansing agents for washing clothes and dishes. Disinfectants are substances } \\
\text { applied to non-living objects to destroy microorganisms that are living on these objects. Bleach is a } \\
\text { strong and effective disinfectant that can be used to disinfect surfaces, remove stains, whiten clothes or } \\
\text { also purify water for drinking in households. CLEAPRO offers these products with the caveat that } \\
\text { customers can bring their own packaging, which takes out a significant part of the costs (for both the } \\
\text { business and customers). } \\
\text { On the economic side, the company offers products which are only at about } 30 \% \text { of the usual price, } \\
\text { giving families economic access to hygiene products or leaving families with higher disposable income } \\
\text { for something else, while generating a surplus to compensate for the initial funding including interests. } \\
\text { Environmentally, the re-use of packaging by customers leads to fewer plastic bottles being used, and } \\
\text { therefore, generating less trash. Socially, the access to hygiene products improves health conditions. }\end{array}$ \\
\hline $\begin{array}{l}\text { Case } 4 \\
\text { Cosmetics } \\
\text { Products } \\
\text { "COSMO" } \\
\text { Interviewee A }\end{array}$ & $\begin{array}{l}\text { Interviewee A was also interviewed for } \\
\text { COSMO, after all the additional materials about } \\
\text { this social business had already been reviewed } \\
\text { by the researchers. As the design was clearly } \\
\text { based on the materials and interview, an } \\
\text { additional interview was not deemed necessary. }\end{array}$ & $\begin{array}{l}\text { - COSMO is a social business producing luxury beauty products for the US market, based on a locally } \\
\text { harvested ingredient - Haitian black castor oil. There are multiple product lines based on it, such as } \\
\text { shampoos and conditioners, body creams, soaps and candles. Castor meal leftover from oil production } \\
\text { can be used as a soil fertilizer or fuel. } \\
\text { The castor oil is sourced from extremely poor, smallholder female farmers working with an agricultural } \\
\text { development NGO. The women are otherwise largely denied access to healthcare and water. The } \\
\text { women are offered a means to earn an income and get access by themselves. } \\
\text { - The product is marketed, for example, in spas and health clubs and cosmetics specialty retailers. }\end{array}$ \\
\hline
\end{tabular}


Accepted version status March 2017; Journal of Business Logistics (JBL)

Table 3: Validity and reliability in this research

\begin{tabular}{|c|c|}
\hline Criteria & Application in this study \\
\hline Construct Validity & $\begin{array}{l}\text { - Incorporating multiple sources of evidence (e.g. internal documents of the } \\
\text { social businesses, interviewees, public information) } \\
\text { - Verification of initial findings by joint review within the research team }\end{array}$ \\
\hline Truth-Value & $\begin{array}{l}\text { Triangulation of data across researchers and supplementing interview data } \\
\text { with further data sources (internal and public), e.g. extraction of } \\
\text { material/information/financial flow overviews from business plans and } \\
\text { other materials, then contrasted and clarified during the interviews } \\
\text { - Member checks (review of interview data as well as analyses by } \\
\text { interviewees) } \\
\text { - Coding by both researchers, who were also each present during the } \\
\text { interviews; multiple iterations of coding }\end{array}$ \\
\hline Transferability & $\begin{array}{l}\text { - Purposeful case selection to ensure that a variety of (TBL sustainability- } \\
\text { oriented) business models is captured in the sample to include variety of } \\
\text { design configurations; } 4 \text { case studies sampled, of which } 3 \text { are presented } \\
\text { with their configurations in this paper } \\
\text { - Coverage of different sectors (e.g. energy, food) } \\
\text { - Reflection on specificities of context (resource scarcity) in interpreting the } \\
\text { results }\end{array}$ \\
\hline Traceability & $\begin{array}{ll}- & \text { Applying a common interview protocol across all cases } \\
\text { - } & \text { Developing a case study data base including multiple data sources (e.g. } \\
\text { interview transcripts, business plans, financial calculations, investor } \\
\text { brochures etc.) }\end{array}$ \\
\hline
\end{tabular}

Adapted from: Ellram 1996; Gibbert et al. 2008; Pedrosa et al. 2012; Yin 2014; Creswell 2014 
Accepted version status March 2017; Journal of Business Logistics (JBL)

Table 4: Financial, physical material and information flow participation of stakeholders at EPRO and CHIFA

\begin{tabular}{|c|c|c|c|}
\hline \multicolumn{4}{|c|}{ Case EPRO } \\
\hline Stakeholders & Financial Flow & Physical Material Flow & Information Flow \\
\hline Bank 1 & $\mathrm{Y}$ & $\mathrm{N}$ & $\mathrm{Y}$ \\
\hline OFID & $\mathrm{Y}$ & $\mathrm{N}$ & $\mathrm{Y}$ \\
\hline AFD & $\mathrm{Y}$ & $\mathrm{N}$ & $\mathrm{Y}$ \\
\hline Red Cross & $\mathrm{Y}$ & $\mathrm{N}$ & $\mathrm{Y}$ \\
\hline French Embassy & $\mathrm{Y}$ & $\mathrm{N}$ & $\mathrm{Y}$ \\
\hline USAID & $\mathrm{Y}$ & $\mathrm{N}$ & $\mathrm{Y}$ \\
\hline ICTP & $\mathrm{Y}$ & $\mathrm{N}$ & $\mathrm{Y}$ \\
\hline Suppliers & $\mathrm{Y}$ & $\mathrm{Y}$ & $\mathrm{Y}$ \\
\hline Total SA (Awango) & $\mathrm{Y}$ & $\mathrm{Y}$ & $\mathrm{Y}$ \\
\hline PUM Expert & $\mathrm{N}$ & $\mathrm{N}$ & $\mathrm{Y}$ \\
\hline ENGO & $\mathrm{Y}$ & $\mathrm{N}$ & $\mathrm{Y}$ \\
\hline Bank 2 & $\mathrm{Y}$ & $\mathrm{N}$ & $\mathrm{Y}$ \\
\hline$Y S B$ & $\mathrm{Y}$ & $\mathrm{N}$ & $\mathrm{Y}$ \\
\hline \multicolumn{4}{|c|}{ Case CHIFA } \\
\hline Stakeholders & Financial Flow & Physical Material Flow & Information Flow \\
\hline Private Customers & $\mathrm{Y}$ & $\mathrm{Y}$ & $\mathrm{Y}$ \\
\hline Hotels & $\mathrm{Y}$ & $\mathrm{Y}$ & $\mathrm{Y}$ \\
\hline Heifer & $\mathrm{N}$ & $\mathrm{N}$ & $\mathrm{Y}$ \\
\hline Ministry of animal production & $\mathrm{N}$ & $\mathrm{N}$ & $\mathrm{Y}$ \\
\hline U.S. \& Dominican Republic & $\mathrm{N}$ & $\mathrm{N}$ & $\mathrm{Y}$ \\
\hline JAMCHI & $\mathrm{Y}$ & $\mathrm{Y}$ & $\mathrm{Y}$ \\
\hline Grameen creative lab & $\mathrm{N}$ & $\mathrm{N}$ & $\mathrm{Y}$ \\
\hline Local Community & $\mathrm{Y}$ & $\mathrm{N}$ & $\mathrm{Y}$ \\
\hline HNGO & $\mathrm{Y}$ & $\mathrm{N}$ & $\mathrm{Y}$ \\
\hline $\begin{array}{l}\text { YSB } \\
\text { Y= Yes; N= No } \\
\text { Those bold/in Italics were } \\
\text { named as key stakeholders }\end{array}$ & Y & $\mathrm{N}$ & $\mathrm{Y}$ \\
\hline
\end{tabular}


Accepted version status March 2017; Journal of Business Logistics (JBL)

Table 5: Sustainable outputs in the four businesses (predominantly via physical chain)

\begin{tabular}{|l|l|l|l|l|}
\hline & EPRO & CHIFA & CLEAPRO & COSMO \\
\hline Outputs & & & & \\
\hline Environmental & & & & \\
\hline Durable & Y & N & N & N \\
\hline Solar driven/renewable energy & Y & N & N & N \\
\hline Reduced packaging waste & N & N & Y & N \\
\hline Social & & & & \\
\hline Promote hygiene (health) & N & N & Y & N \\
\hline Less chemicals in food (health) & N & Y & N & N \\
\hline Cleaner Tech, less charcoal fumes (health) & Y & N & N & N \\
\hline $\begin{array}{l}\text { Additional light for homework (reduced eye } \\
\text { strain; health) }\end{array}$ & Y & N & N & N \\
\hline Economic & & & & \\
\hline For-profit pricing of products/business model & Y & Y & Y & Y \\
\hline $\begin{array}{l}\text { Product pricing leaves additional income } \\
\text { available for other needs }\end{array}$ & Y & Y & Y & Y \\
\hline Y= Yes; N= No & & & & \\
\hline
\end{tabular}

Table 6: Sustainable outcomes in the four businesses (predominantly via support chains)

\begin{tabular}{|l|l|l|l|l|l|}
\hline Outcomes & EPRO & CHIFA & CLEAPRO & COSMO & $\begin{array}{l}\text { Main } \\
\text { support chain }\end{array}$ \\
\hline Environmental & & & & & \\
\hline Closed loop waste management & N & Y & N & Y & Information \\
\hline Social & & & & & \\
\hline Better education & N & Y & N & N & Financial \\
\hline Provide jobs for disadvantaged group & N & N & N & Y & Financial \\
\hline Business to fund a social project & N & Y & N & N & Financial \\
\hline Community pride/commitment & N & Y & N & N & Information \\
\hline Economic & & & & & \\
\hline $\begin{array}{l}\text { Promote financial support for customers to buy } \\
\text { products }\end{array}$ & Y & Y & N & N & Financial \\
\hline Money goes back to community (e.g. teachers) & N & Y & N & N & Financial \\
\hline Y= Yes; N= No & & & & & \\
\hline
\end{tabular}


Accepted version status March 2017; Journal of Business Logistics (JBL)

\section{APPENDIX A}

\section{INTERVIEW GUIDE}

\section{Background Questions}

1. State your name and describe your position in the business and how long you have been part of this business?

2. What is your professional background prior to establishing this business?

3. Describe the structure of the business (if possible, then provide an organization chart).

4. Approximately how many employees are involved in the business at all locations?

\section{Understanding the Network and Set-up of the business}

5. How did this idea to establish the chicken farms to finance schools come up? [This question was always adapted to the specific business, here exemplary for CHIFA]

6. Describe in your own words the process steps involved in implementing and maintaining a successful social business model and a little bit of what is involved (and who is involved) in each step. Start from the time that the funding/loan is approved.

7. Discuss the amount of time involved in each step.

8. Discuss the stakeholders that are directly or indirectly involved in the business.

\section{Your social business}

9. What was your specific motivation for this social business?

10. How did you learn about YSB? How did you get in touch?

11. How has YSB helped you in establishing the business?

12. Who else has helped/played a major part in establishing the business?

13. How do you define "success" in your social business model?

14. Do you consider the success so far sustainable?

15. What do you see as the primary barriers to success?

16. What are the primary facilitators of success?

17. Can you describe the environmental, social, economic impacts of your social business?

18. Were there differences between the planned and actual outcomes? How were these differences addressed?

19. Are there measures and metrics used to validate your performance and the business model's performance?

\section{Material/Service Flows}

20. Discuss the process flows for materials and services - in terms of plan, source, make, deliver.

21. Is there any type of advertising? What are the main attributes attracting customers?

22. What is the variety of the offering (narrow versus broad)? Are there plans to make any changes to these offerings?

\section{Financial Flows}

23. Discuss the flow and frequency of both upstream and downstream financial flows.

24. Are the investments given in a "lump sum" to the entrepreneur? If so, who manages the money?

25. How are payments made to suppliers, employees, investors? 
Accepted version status March 2017; Journal of Business Logistics (JBL)

\section{Information Flows}

26. Describe and discuss the flow of information both upstream and downstream.

27. What types of information are shared?

28. How often is that information shared?

29. What means of communication are used?

\section{Wrap-up}

30. From your perspective is there anything that we should have asked about that we didn't that might be relevant for the research?

31. As additional questions arise, can we follow-up with you? 
Accepted version status March 2017; Journal of Business Logistics (JBL)

\section{APPENDIX B}

\section{YUNUS SOCIAL BUSINESS PROFILE, Source: YSB (2014, 3-5).}

\section{Principles of Social Business:}

1. Goal: To solve social or environmental problems

2. Financial and economic sustainability

3. Investors repaid; no further private financial return

4. Profit funds expansion, improvements or seeding other social businesses

5. Environmentally conscious

6. Market wages; better working conditions

7. Do it with joy

YSB applies business approaches to the world of social development. It has developed an innovative Incubator Fund methodology which bridges the gap between social businesses and social investors and donors. While the Incubator searches, coaches and selects social businesses, the Fund provides debt and equity financing to the businesses after a thorough due diligence process. While a traditional investor invests for financial gain, a Social Investor invests to benefit society. A Social Investor's goal is to maximize social return on his or her investment and is thus motivated to support the most effective social businesses. By investing in a Social Business Incubator Fund, the Social Investor benefits from standardized annual and semi-annual reports that detail both financial and social impact performance. The Social Investor will recoup up to the full nominal value of his or her initial investment. All profits from the social businesses are committed to be recycled into new social businesses.

The Fund receives capital from donors and investors. After a thorough due diligence process, the Fund invests this capital into social businesses that have been selected and prepared by the Incubator. As the social businesses pay back the capital, the Fund reinvests it into other social businesses, and/or returns it to philanthropic investors in proportion to their share of the total capital contributed, up to the nominal value of his or her initial investment.

The incubator is responsible for searching and creating social business opportunities and helping the social businesses develop a strong and coherent business plan. It also provides coaching and capacity building to social business entrepreneurs, allowing access to useful networks that help them expand their businesses.

\section{Searching and Creating Social Business Opportunities}

YSB receives hundreds of social business plans on an annual basis. The Incubator is responsible for screening the plans and moving forward with a handful that demonstrate the highest potential. To attract entrepreneurs, the Incubator holds Social Business Plan competitions, public events and workshops.

\section{Developing Social Business Plans}

Once pre-selected, the Incubator works with the business to improve the social business plan and prepare the business for investment. At this stage, the Incubator will focus on whether the social business will be financially self-sustainable and determine how to maximize its social impact.

\section{Training, Coaching and Capacity Building}

Pre- and post-investment, the Incubator continuously seeks to broaden the skill sets and capabilities of its entrepreneurs. This includes personal coaching and courses on topics such as business accounting or technical industry-specific topics. The Incubator is supported by a network of corporate pro-bono partners.

\section{Networks}

The Incubator provides access to its local and international networks of potential buyers, partners and experts that lend support to the social businesses. 